\title{
EXCAVACIONES EN LOS PATIOS NORTE DEL CONJUNTO AMURALLADO DE CHOL AN (EX PALACIO RIVERO), CHAN CHAN, PERÚ
}

\author{
EXCAVATIONS IN THE NORTH COURTYARDS OF THE CHOL AN WALLED \\ COMPOUND IFORMERLY PALACIO RIVEROI, CHAN CHAN, PERU
}

Denis Elvis Correa-TrigosoA \& Fabián Soberón Winchonlóng ${ }^{B}$

El objetivo de las excavaciones fue determinar el uso y función de los patios 1, 2 y 7, en el Conjunto Amurallado de Chol An perteneciente al Complejo Arqueológico Chan Chan, y establecer una secuencia ocupacional y constructiva para este sector. Se planteó como metodología la excavación de trincheras y cateos alrededor de los muros delimitantes de los patios. Como resultado se registraron elementos arquitectónicos tempranos asociados al muro de tapia, remodelaciones y muretes que encierran ambientes utilizados para la actividad doméstica. Igualmente, se recuperó material cultural del momento más tardío, permitiendo establecer cuatro momentos constructivos y dos ocupacionales, donde la más tardía cambia la función y uso de los patios.

Palabras clave: Remodelación, Doméstico, Arquitectura, Intermedio Tardío, Tapia, Inca, Reocupación y patio.

The purpose of the excavations was to determine the use and function of the courtyards 1, 2 and 7, in the Chol An walled compound in the Chan Chan archaeological complex, and to establish an occupational and building sequence for this sector. The methodology consisted in digging trenches and prospecting around the perimeter walls of the courtyards. As a result, it was possible to identify early architectural elements associated with the tapia (mud) wall, remodeling, and walls enclosing spaces used for domestic activity. Additionally, cultural material associated with the later phase was recovered, which allowed to determine four building phases and two occupational moments, where the later occupation radically changed the function and, the use of the courtyards.

Keywords: Remodeling, Domestic, Architecture, Late Intermediate, Wall, Inca, Reoccupation and courtyard.

\section{INTRODUCCIÓN}

En este artículo se presentan los resultados de las intervenciones arqueológicas realizadas durante el proyecto "Investigación para la conservación de la plaza ceremonial 1 y patio noreste del Conjunto Amurallado Chol An -Complejo Arqueológico-Chan Chan" (Soberón 2014), a cargo de la Unidad Ejecutora 006, Complejo Arqueológico Chan Chan, Ministerio de Cultura. La investigación tuvo como objetivos determinar las características arquitectónicas de las estructuras registradas y la función y uso de los patios principales en el Conjunto Amurallado Chol An. Se realizaron dos etapas anteriores a nuestra intervención. La primera se enfocó en los muros de tapia este y oeste (denominados por el proyecto como perimetrales internos), estableciéndose que, asociadas a los muros de tapia, se registran estructuras tempranas y tardías. En la segunda etapa se intervinieron los muros perimetrales norte, este, oeste y sur, así como también el muro perimetral interno norte, descubriendo que, primero se construyeron los muros de tapia (perimetrales internos) y en otro momento se elaboraron los muros perimetrales (Paredes 2013).

\footnotetext{
A Denis Elvis Correa-Trigoso, Complejo Arqueológico Chan Chan, Trujillo, Perú. E-mail: dcorreatrigoso@gmail.com

B Fabián Eduardo Soberón Winchonlóng, Complejo Arqueológico Chan Chan, Trujillo, Perú. E-mail: fabiosoberon@hotmail.com
} 


\section{CHAN CHAN Y EL CONJUNTO AMURALLADO CHOL AN}

El Imperio Chimú fue una sociedad que se desarrolló alrededor del 900-1470 DC (Campana 2006, Moore \& Mackey 2008) durante el Período Intermedio Tardío (1100-1470 DC). Fue una sociedad jerarquizada, con una larga sucesión de linajes de gobernantes, llamados Chimu Capac por los incas (Rostworowski 2011: 259). Los límites territoriales fueron el valle de Zaña al norte y el valle de Santa al sur (Moore \& Mackey 2008) (fig. 1). En la cúspide de su expansión territorial fueron conquistados por los incas en 1470, siendo Minchançaman, el último gobernante quien cayó derrotado a manos de Tupac Inca Yupanqui (Vargas 1936). Los chimús basaron su eje económico en las actividades agrícolas, sustentadas en una amplia red de canales de regadíos (Risco 2013), así como en un gran desarrollo de la textilería y de la metalurgia (Cornejo et al. 2005). La capital de este imperio fue la metrópoli de Chan Chan, localizada en la Provincia de Trujillo, Departamento de La Libertad, en la costa norte del Perú. Alcanzó una extensión territorial aproximada de $8 \mathrm{~km}$ durante el máximo desempeño de sus funciones (Ravines 1980b).

La capital ofrecía un ordenamiento arquitectónico claramente demarcado por cuatro sectores: el primero, conformado por diez conjuntos amurallados, los cuales eran las residencias de los gobernantes chimús y lugar donde se realizaban las ceremonias; el segundo, por las áreas de vivienda de la nobleza secundaria, también conocida como arquitectura intermedia; el tercero corresponde a la zona urbana de la capital donde habitaba la población en recintos aglutinados, pequeños e irregulares; finalmente, el cuarto sector, estaba constituido por las estructuras rurales ubicadas en la periferia de las cuatro zonas antes mencionadas (Ravines 1980b).

Los diez conjuntos amurallados, considerados anteriormente como palacios, tenían una denominación diferente a la actual (tabla 1) (Paredes 2010). Su agrupación responde a una una secuencia relativa de tres etapas constructivas de crecimiento en Chan Chan (Kolata 1980). Durante el momento temprano o inicial fueron edificados Chayhuac An, Xllangchic An y Tsuts An, seguidos por un período medio durante el cual se construyen Fechech An y Utzh An, siendo finalmente erigidos Fochic An, Ning An, Nain An, Nik An y Chol An en la etapa tardía o imperial. El conjunto amurallado denominado Chol An se ubica en la parte suroeste del Complejo Arqueológico Chan Chan y limita por el norte con los Conjuntos Amurallados Laberinto y Tello, por el sur con las costas marinas, por el este con los Conjuntos Amurallados Chayhuac An y Nik An (fig. 2).

El primer trabajo arqueológico en el conjunto amurallado fue realizado en el marco del Proyecto Chan Chan-Valle de Moche, realizado entre los años 19691974, siendo dirigido por Moseley y Mackey (Ravines 1980a, Moseley \& Day 1982). Day interviene arqueológicamente el Conjunto Amurallado Chol An y logra establecer que, en relación con la organización espacial, la disposición de los corredores y los accesos tenían la función de restringir el ingreso a las demás áreas para aislar los diferentes ambientes y dirigir el flujo de los individuos que entraban al conjunto amurallado. Señala también que en el sector norte de Chol An existen patios de cocina con presencia de fogones y considera que en estos espacios se realizaba la preparación de alimentos (Day 1980: 155, 1982: 57).

Producto de las diversas excavaciones en este conjunto amurallado (Day 1973, 1980; Paredes 2013) es posible establecer que se encuentra delimitado por una doble muralla, siendo la exterior de adobe y la interior de tapia. Se observan seis patios con cuatro accesos. De estos, los de mayores dimensiones se encuentran siempre asociados a una rampa. En el patio 1 de Chol An, no se evidencia algún tipo de decoración en sus paramentos. Asimismo, se registran dentro del conjunto amurallado contiene en su interior una plataforma funeraria, audiencias, depósitos, sistemas de accesos y corredores internos.

\section{LAS EXCAVACIONES ARQUEOLÓGICAS}

Para lograr los objetivos se construyeron 14 trincheras y se realizaron 27 cateos a lo largo de los muros que delimitan los patios 1, 2, 3 y 7. Para un mejor registro, se dividió el área de intervención en subsectores; de este modo, la parte norte del conjunto amurallado se subdividió en los patios 1, 2, 3, 4, 5, 6 y 7 (fig. 3).

Se denominaron pisos aquellas superficies elaboradas arquitectónicamente y asociadas a las estructuras verticales por una media caña; y apisonados, las superficies compactas con relieve irregular que no tienen un acabado pulido como los anteriores, y se vinculaban con la actividad humana. 


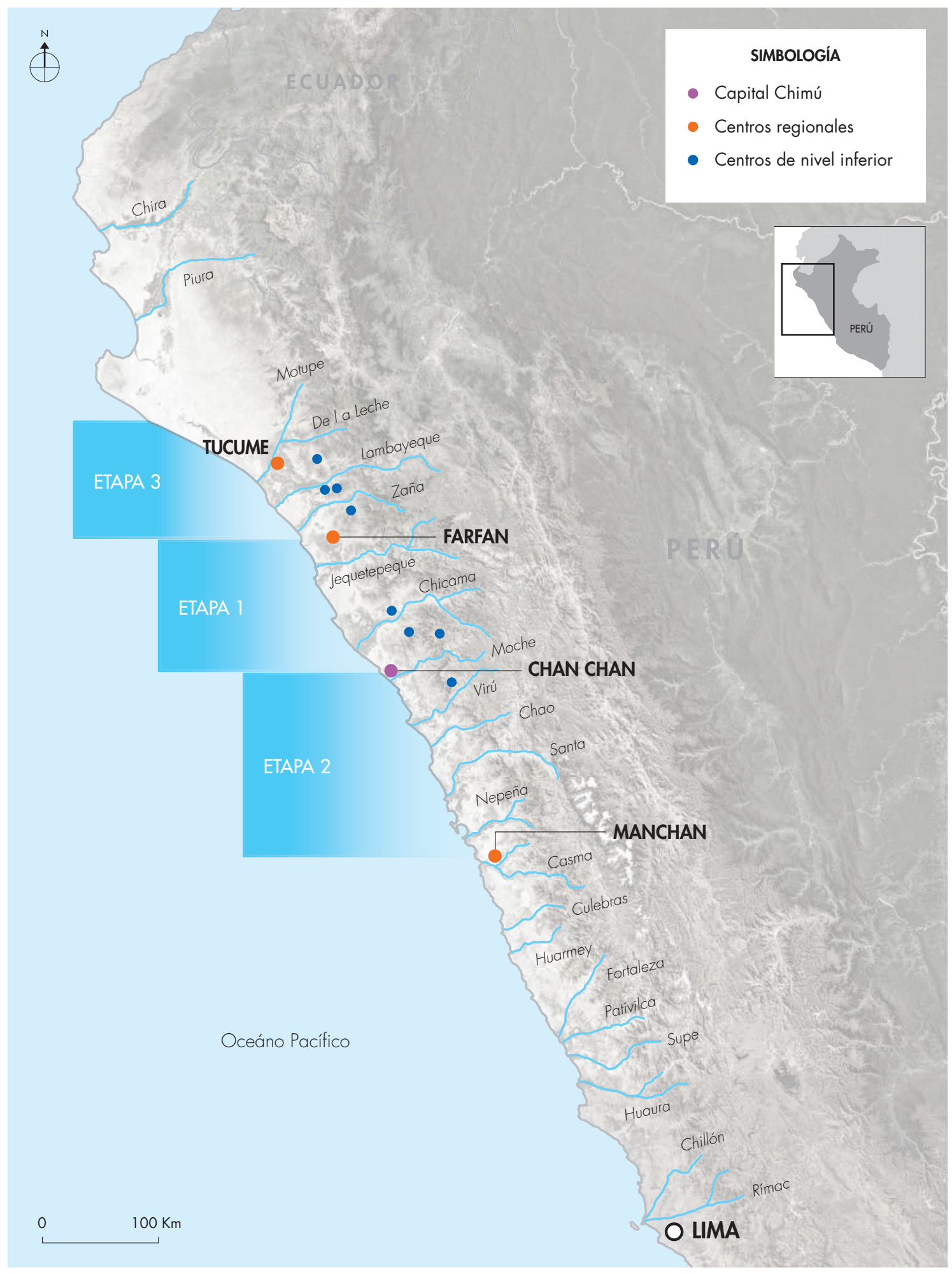

Figura 1. Centros regionales chimús y sus etapas de expansión (modificado de Moore \& Mackey 2008: 788). Figure 1. Chimú regional centers and their expansion stages (adapted from Moore \& Mackey 2008: 788). 
Tabla 1. Distintas denominaciones de las residencias de los gobernantes chimús en el Complejo Arqueológico Chan Chan. Table 1. Different denominations of the residencies of the Chimú rulers in the Chan Chan Archaeological Complex.

\begin{tabular}{c|c}
\multicolumn{2}{c}{ COMPLEJO ARQUEOLÓGICO CHAN CHAN } \\
DENOMINACIÓN \\
ANTERIOR & DENOMINACIÓN \\
ACTUAL \\
\hline Palacios & Conjuntos Amurallados \\
\hline Bandelier & Nain An \\
\hline Chayhuac & Chayhuac An \\
\hline Gran Chimú & Utzh An \\
\hline Laberinto & Fechech An \\
\hline Rivero & Chol An \\
\hline Squier & Fochic An \\
\hline Tello & Tsuts An \\
\hline Tschudi & Nik An \\
\hline Uhle & Xllangchic An An \\
\hline
\end{tabular}

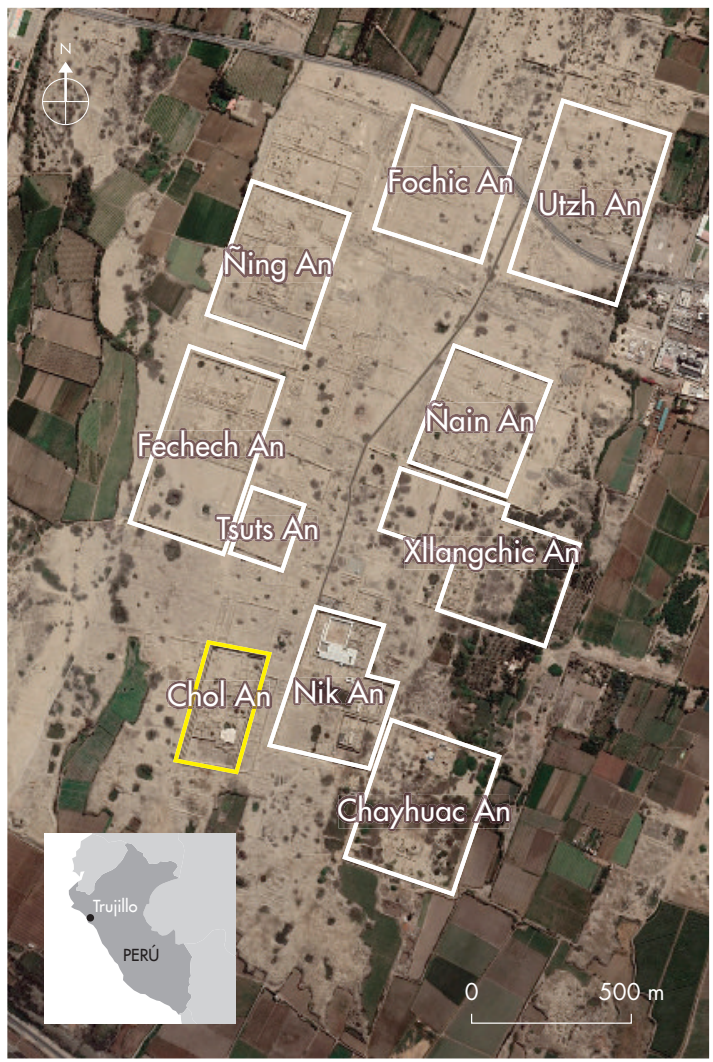

Figura 2. Ubicación del Conjunto Amurallado Chol An dentro del Complejo Arqueológico Chan Chan. Figure 2. Location of the Chol An Walled Compound inside the Chan Chan Arcaheological Complex.

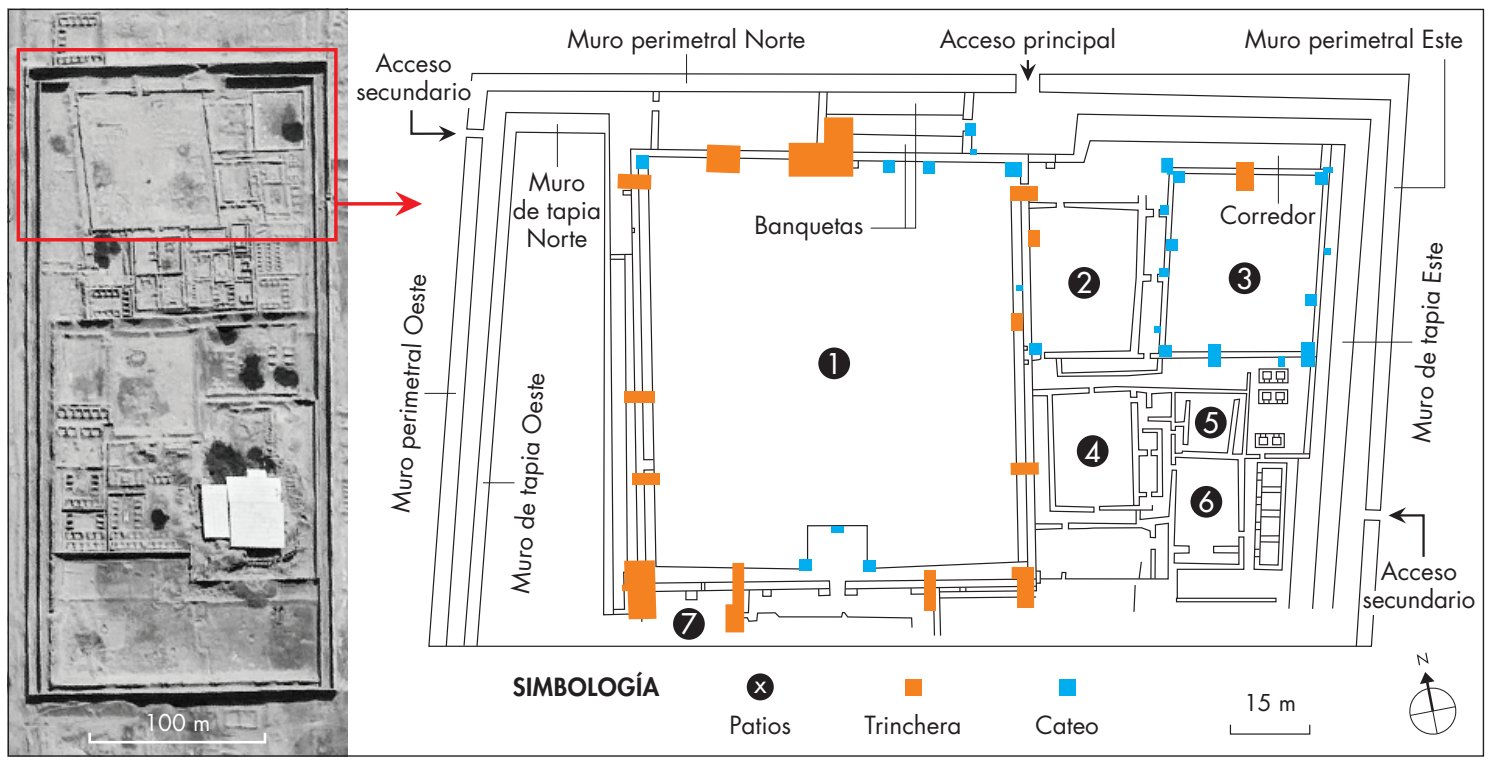

Figura 3. Unidades de excavación en la zona norte del Conjunto Amurallado Chol An. Figure 3. Excavation units in the northern part of the Chol An Walled Compound. 


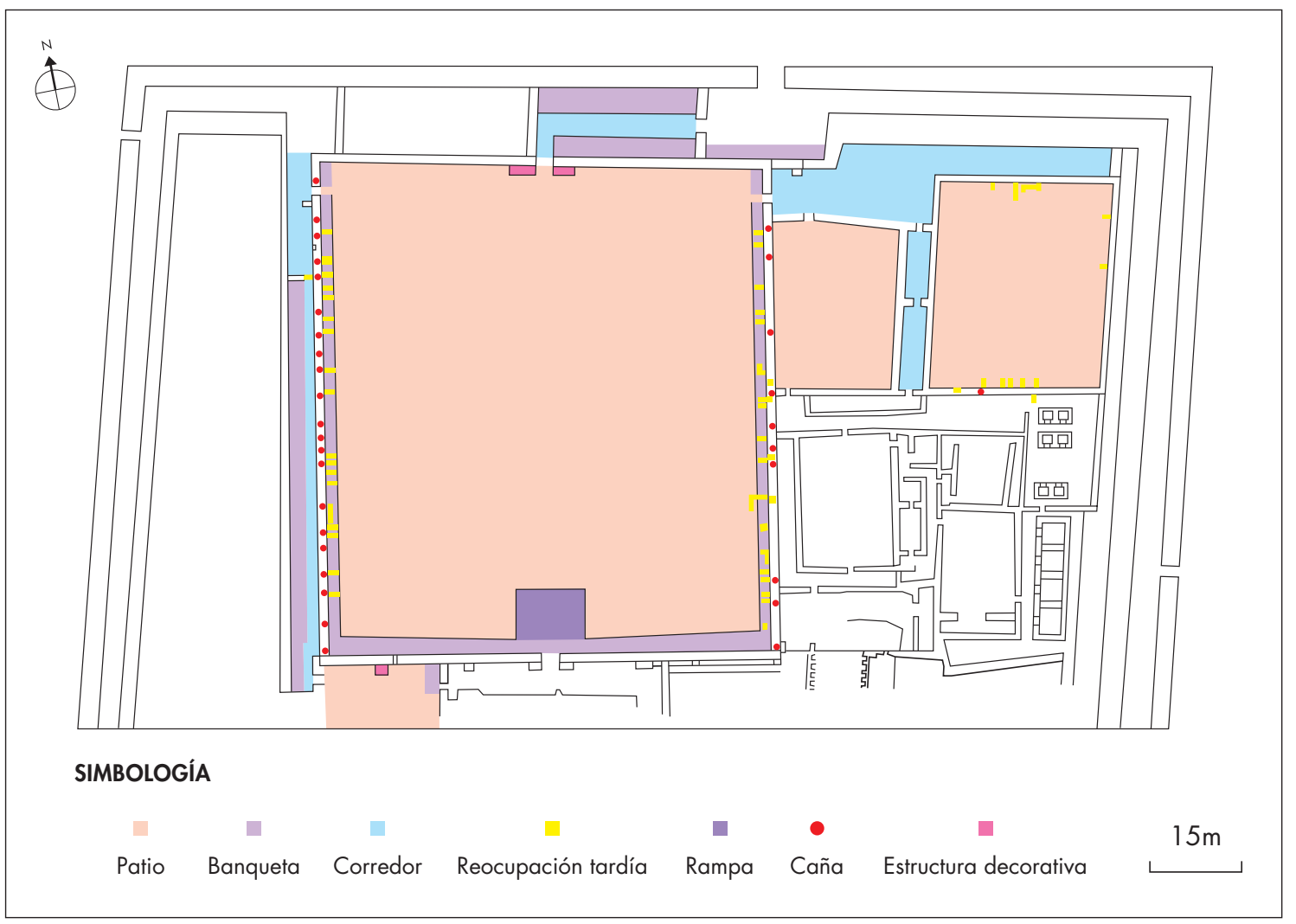

Figura 4. Resultados de las excavaciones en la zona norte del Conjunto Amurallado Chol An. Figure 4. Results of the excavations in the northern part of the Chol An Walled Compound.

\section{RESULTADOS}

Producto de las excavaciones fue posible definir ambientes como patios y corredores, estructuras decorativas, elementos arquitectónicos (banquetas y rampas), accesos, así como momentos constructivos y reocupación tardía (fig. 4).

\section{Los patios}

El patio 1 se ubica en el lado norcentral del conjunto amurallado, limita por el norte con la explanada norte, corredor norte y parte de la antesala. Por el este con los patios 2 y 4 . Al sur con el patio 6 y los corredores de las audiencias. Al oeste con la explanada noroeste y el corredor con banqueta. El patio está orientado de norte a sur, con dimensiones de 72,47 $\mathrm{m}$ de ancho por $78,66 \mathrm{~m}$ de largo, ocupando un área de 5705,75 $\mathrm{m}^{2}$. Está conformado por cuatro muros delimitantes con medidas desde 2,50 m a 3,20 m de altura y $1,40 \mathrm{~m}$ de ancho en su base. Dichos muros de adobes altos y planos (pequeños), presentan un marcado talud y fueron construidos con mortero de barro y se utilizaron rocas para las bases. Este tipo de material constructivo solo puede ser observado en la base del muro norte. Los muros este, oeste y sur tienen base de adobe, siendo esta última estructura la más temprana en la construcción de los muros delimitantes del patio.

El uso de la piedra en el muro norte se debe a que se desmontó una sección del muro de tapia norte para dar paso a nuevas construcciones, levantándolo sobre parte de la base del muro de tapia. Esto fue posible dedeterminar por las características arquitectónicas que se lograron definir durante la excavación del muro de tapia norte (Paredes 2013). Este ambiente presenta cinco vanos de acceso. El primero se ubica en la parte central del muro norte y es considerado como el vano principal, cuya función fue dar acceso al patio 1 al ingresar en el 
conjunto amurallado, y contiene dos estructuras decorativas adosadas al muro norte. El segundo y el tercero, situados en los muros oeste, dan paso al patio 2 por el este y a la explanada noroeste al oeste. En la parte central del muro sur se encuentra el cuarto acceso, permitiendo un entrada a la parte alta, área destinada a las audiencias y para depósitos. El quinto vano, en la parte central del muro oeste, fue un antiguo ingreso, sellado durante el segundo momento constructivo. La parte interna del patio, presenta un sistema de banquetas dispuestas en el paramento interno de los muros este, oeste, norte y sur. También se observa la presencia de una rampa de $5,78 \mathrm{~m}$ de ancho por 11,63 $\mathrm{m}$ de largo.

El patio 2 se localiza en el lado noreste del conjunto amurallado y limita por el norte con el corredor norte, por el este con el patio 1, por el sur con el patio 4 , y por el oeste con el patio 3. Se encuentra orientado de norte a sur, tiene $20,80 \mathrm{~m}$ de ancho y $26,85 \mathrm{~m}$ de largo con un área total de $558,48 \mathrm{~m}^{2}$. El patio 2 está conformado por cuatro muros delimitantes de $2,10 \mathrm{~m}$ a $3,20 \mathrm{~m}$ de altura y $0,85 \mathrm{~m}$ de ancho en su base. Los muros fueron construidos con adobes y mortero de barro. Este ambiente presenta dos vanos de acceso, el primero se ubica en la parte central del muro norte, facilitando el ingreso al patio 2 desde el patio 1; el segundo, en el extremo oeste del muro sur para acceder al patio 4 .

El patio 3 está en el lado noreste del conjunto amurallado, limita por el norte con el corredor norte, por el este con el patio 2, por el sur con el patio 5, y por el oeste con el corredor este. Se encuentra orientado de norte a sur, mide $28,20 \mathrm{~m}$ de ancho y 33,45 $\mathrm{m}$ de largo, su área total es de $943,29 \mathrm{~m}^{2}$. El patio 3 está conformado por cuatro muros delimitantes de $1,03 \mathrm{~m}$ a 2,27 $\mathrm{m}$ de altura y 0,85 $\mathrm{m}$ de ancho en su base. Los muros fueron construidos con adobes y mortero de barro. Se estableció que el muro sur se proyectó en un inicio hasta el muro de tapia este, pero que luego se desmontó para cerrar el patio. Este ambiente presenta dos vanos de acceso. El primero y principal se ubica en el extremo noreste del muro oeste, su función era permitir la entrada al patio 3 . El segundo fue un antiguo acceso que fue sellado durante el segundo momento constructivo, estaba ubicado en la parte central del muro oeste y daba acceso al patio 3 por el lado oeste.

El patio 7 está localizado en la parte central del conjunto amurallado y limita por el norte con el patio 1 , por el este con la explanada noreste, por el sur y oeste con las audiencias. Se encuentra orientado de norte a sur. Los muros fueron construidos con adobes y mortero de barro. Este ambiente presenta dos vanos de acceso, el primero se ubica al oeste y conecta el patio con el corredor con banqueta al oeste. El segundo está situado al este, dando acceso al corredor de las audiencias. Asociado a esta entrada se registra una banqueta con rampa, además de una hornacina y una estructura decorativa adosada el muro sur del patio 1 .

\section{Los corredores}

Los patios se interconectan por medio de un conjunto de corredores que se encuentran orientados en todas las direcciones, con diversas dimensiones y en algunos casos se agregan elementos arquitectónicos, como banquetas, lo que supone un cambio en la función de estos ambientes. El corredor norte se encuentra asociado al acceso principal del conjunto. Aquí se agregan dos banquetas en paralelo y dos muros que recortan sus dimensiones originales con la finalidad de generar una antesala para los ingresantes al patio 1 (fig. 5). Similar forma se registra en el corredor ubicado al oeste del patio 1, donde se observa la presencia de una banqueta al oeste del ambiente y lo abarca en su totalidad.

\section{Las banquetas}

Este elemento arquitectónico se dispone corredores y patios. En el corredor norte se registran dos banquetas. La banqueta sur tiene 3,21 de ancho por 23,05 $\mathrm{m}$ de largo, y la banqueta norte 4,25 $\mathrm{m}$ de ancho por $26 \mathrm{~m}$ de largo; ambas de 0,60 m de altura. Al frente del acceso principal del conjunto se registra una banqueta de $3,68 \mathrm{~m}$ de ancho, 19,55 $\mathrm{m}$ de largo y 0,44 $\mathrm{m}$ de altura, asociada con el paramento norte del muro norte del patio 1 . En el patio 1 hay tres banquetas junto a los muros oeste, este y sur. La banqueta oeste mide 1,90 m de ancho, 76,20 m de largo y $0,22 \mathrm{~m}$ de altura y se encuentra dividida por el acceso oeste en dos partes. La banqueta este presenta similares características, aunque durante la ocupación tardía, este elemento arquitectónico fue desmontado por secciones. La banqueta sur, de 3,26 $\mathrm{m}$ de ancho, 72,35 m de largo y 1,14 m de altura, se encuentra asociada con la rampa que conecta los patios 1 y 7 . En el corredor oeste del patio 1 se registra una banqueta de 2,54 $\mathrm{m}$ de ancho, 61,56 m de largo y 1,72 $\mathrm{m}$ de alura. En el patio 7 se identificó una banqueta de 2,66 m de ancho, 2,42 $\mathrm{m}$ de largo y $0,84 \mathrm{~m}$ de altura, asociada con una rampa que conecta con el área de audiencias. 


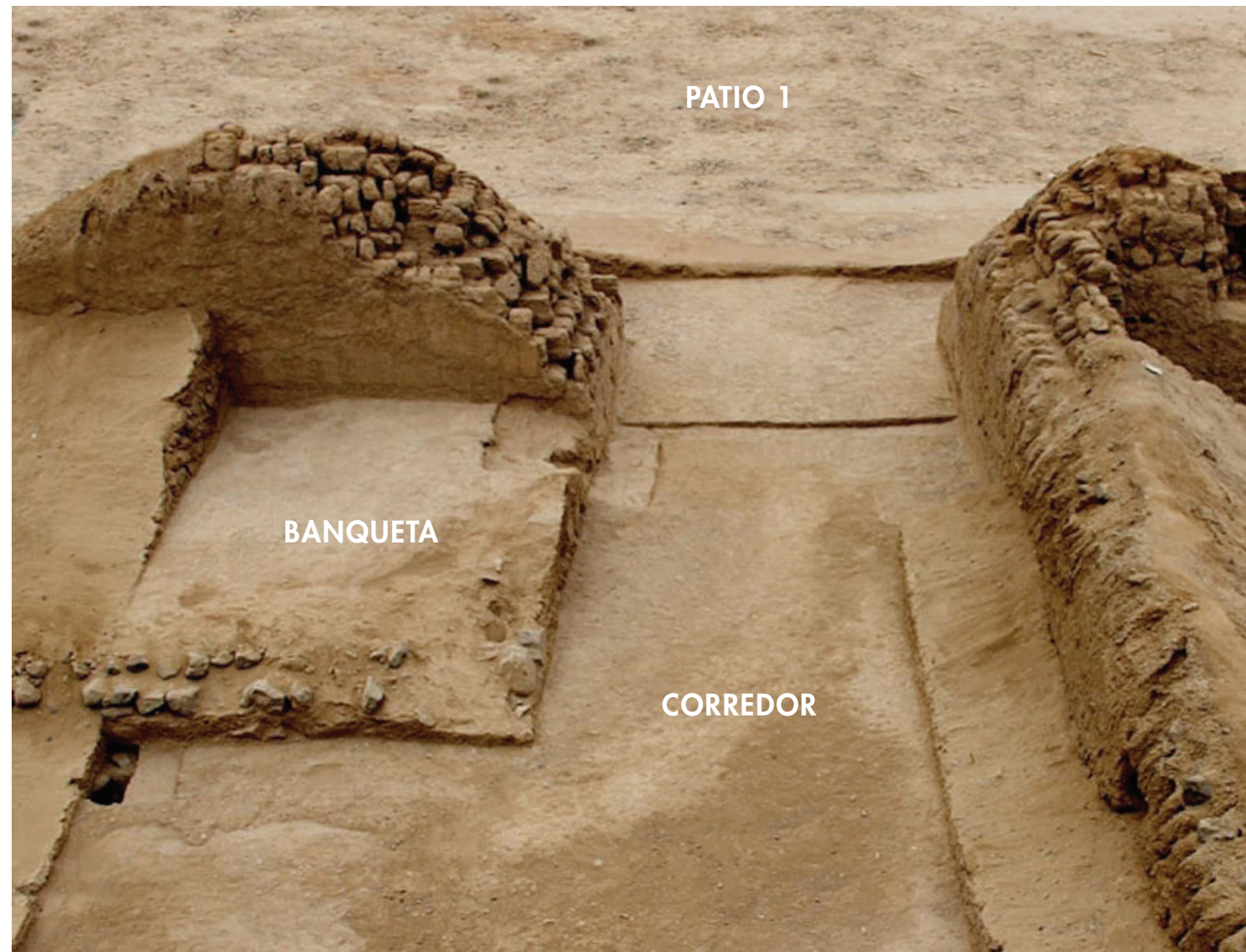

Figura 5. Corredor y acceso norte del patio 1, con una banqueta adosada empleada como una antesala de los ingresantes al conjunto amurallado. Figure 5. Corridor and northern entrance of courtyard 1, with a bench attached used as anteroom for those entering the walled compound.

Las banquetas fueron construidas de adobes y mortero de barro, luego se colocaba la piedra canteada a lo largo del parapeto para ser posteriormente enlucido. Estos elementos estructurales fueron empleados como áreas de reposo, donde las personas que ingresaban tenían la posibilidad de descansar y/o colocar los diversos objetos que llevaban durante la realización de ceremonias en los patios de este conjunto amurallado. Las banquetas de los patios 1 y 7 se complementaban con las rampas, generando arquitectónicamente un nivel homogéneo que conectaba el desnivel entre dos áreas y facilitaba el acceso a otras zonas dentro del conjunto.

\section{Las estructuras decorativas}

Durante las excavaciones fueron registradas tres estructuras adosadas, que tenían como finalidad la decoración. En el patio 1 hay dos estructuras, ubicadas en el paramento sur del muro norte del patio 1 (fig. 6). Están construidas como un solo bloque de adobes, presentando un tramado en hileras alternas de soga y cabeza, manteniendo la disposición de costilla, con un promedio de 1,42 $\mathrm{m}$ de longitud por 3,70 $\mathrm{m}$ de ancho. Luego de la construcción del bloque, se le adosa una pequeña estructura central con una cavidad en el interior denominada nicho. Cada estructura presenta cuatro pilastras, las cuales forman parte de la trama y el bloque. Estas pilastras se dividen en dos pilastras externas que delimitan la estructura, con un promedio de $0,62 \mathrm{~m}$ de longitud por $0,60 \mathrm{~m}$ de ancho; y dos pilastras internas que delimitan la pequeña estructura central, con un promedio de 0,53 $\mathrm{m}$ de largo por $0,45 \mathrm{~m}$ de ancho. El nicho tiene $0,50 \mathrm{~m}$ de largo por $1 \mathrm{~m}$ de ancho, aproximadamente, con una pequeña abertura rectangular de $0,50 \mathrm{~m}$ de profun- 


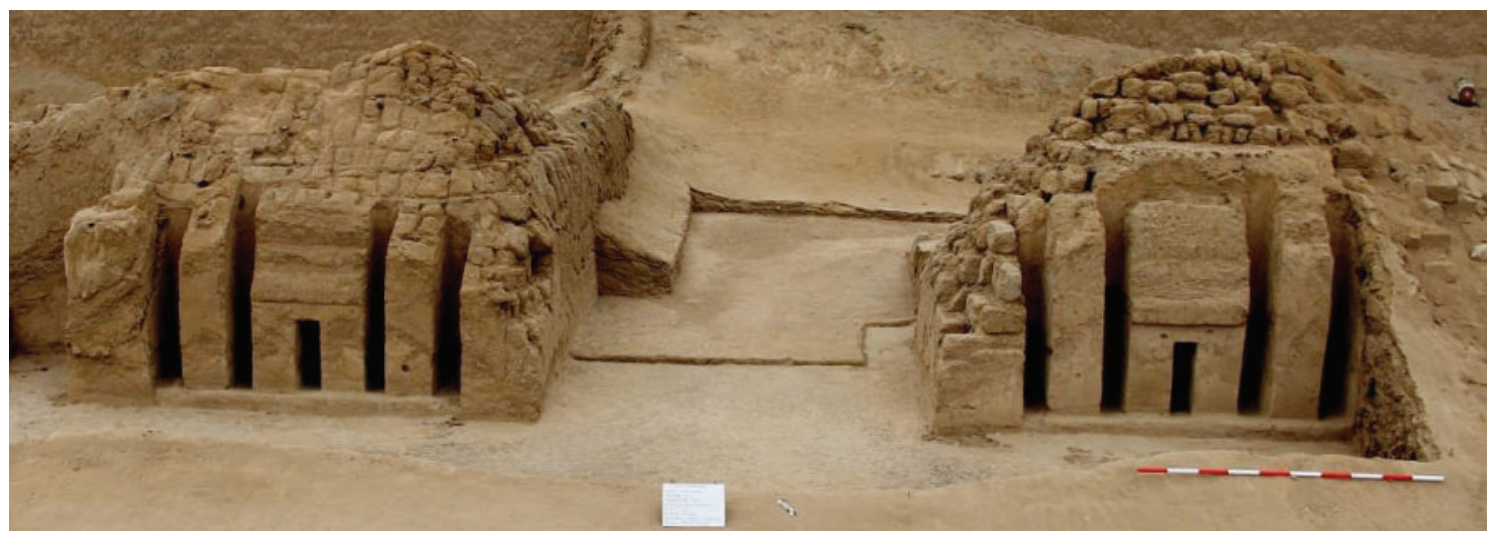

Figura 6. Estructuras decorativas adosadas al muro norte y junto al acceso norte del patio 1. Figure 6. Decorative structures attached to the north wall and beside the north entrance to courtyard 1.

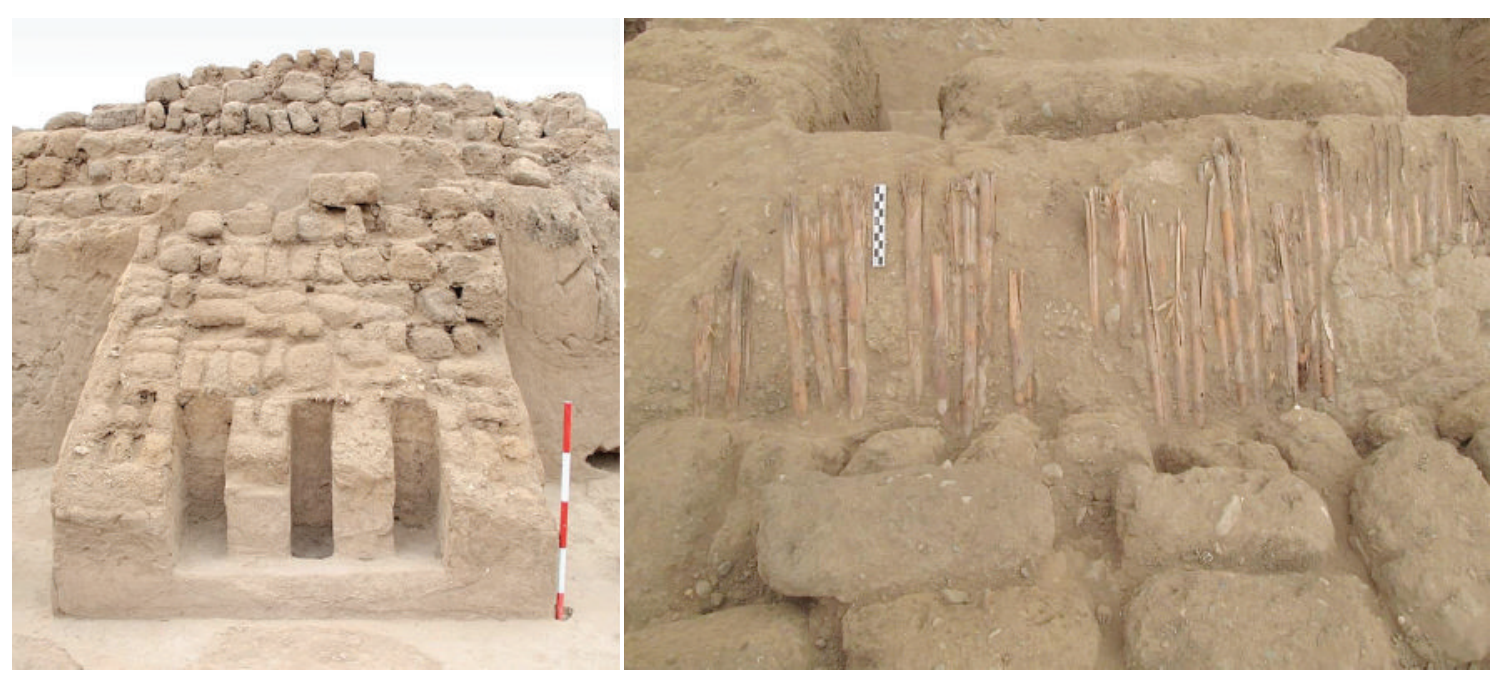

Figura 7. Estructura decorativa registrada en el patio 7 (izquierda) y restos de carrizos pertenecientes a la cubierta registrada en la estructura decorativa del patio 1 (derecha). Figure 7. Decorative structure recorded in courtyard 7 (left) and reeds remains from the roof recorded in the decorative structure of courtyard 1 (right).

didad, 0,20 $\mathrm{m}$ de ancho, $1,20 \mathrm{~m}$ de altura y $0,05 \mathrm{~m}$ de alero. Entre las pilastras se observan espacios de 0,20 $\mathrm{m}$ de ancho promedio, siendo la longitud la misma de las pilastras, asociándose con el piso del patio 1. No se observa evidencia de pigmentos en los paramentos de ambas estructuras.

En el patio 7 se registra otra estructura decorativa adosada al muro sur del patio 1 . Presenta $2,05 \mathrm{~m}$ de largo por 1,50 m de ancho y 1,57 $\mathrm{m}$ de altura máxima conservada. Cuenta con tres pilastras y tres espacios entre ellas. La primera pilastra mide 0,30 $\mathrm{m}$ de largo por $0.20 \mathrm{~m}$ de ancho y $0,61 \mathrm{de}$ alto; la segunda mide 0,25 de largo por $0,19 \mathrm{~m}$ de ancho y $0,66 \mathrm{~m}$ de alto; y la tercera mide $0,30 \mathrm{~m}$ de largo, $0,20 \mathrm{~m}$ de ancho y $0,59 \mathrm{~m}$ de alto. Estas estructuras incluían cubierta de cañas (lo que también se registró en el patio 1), con un diámetro promedio de $0,03 \mathrm{~m}$, colocadas de manera transversal a la estructura, la cuales fueron elaboradas con Phragmites australis "carrizo" y revestidas en su parte exterior con mortero de barro. En el patio 7 se registraron improntas y restos de carrizo en la cubierta de dichas estructuras (fig. 7). 


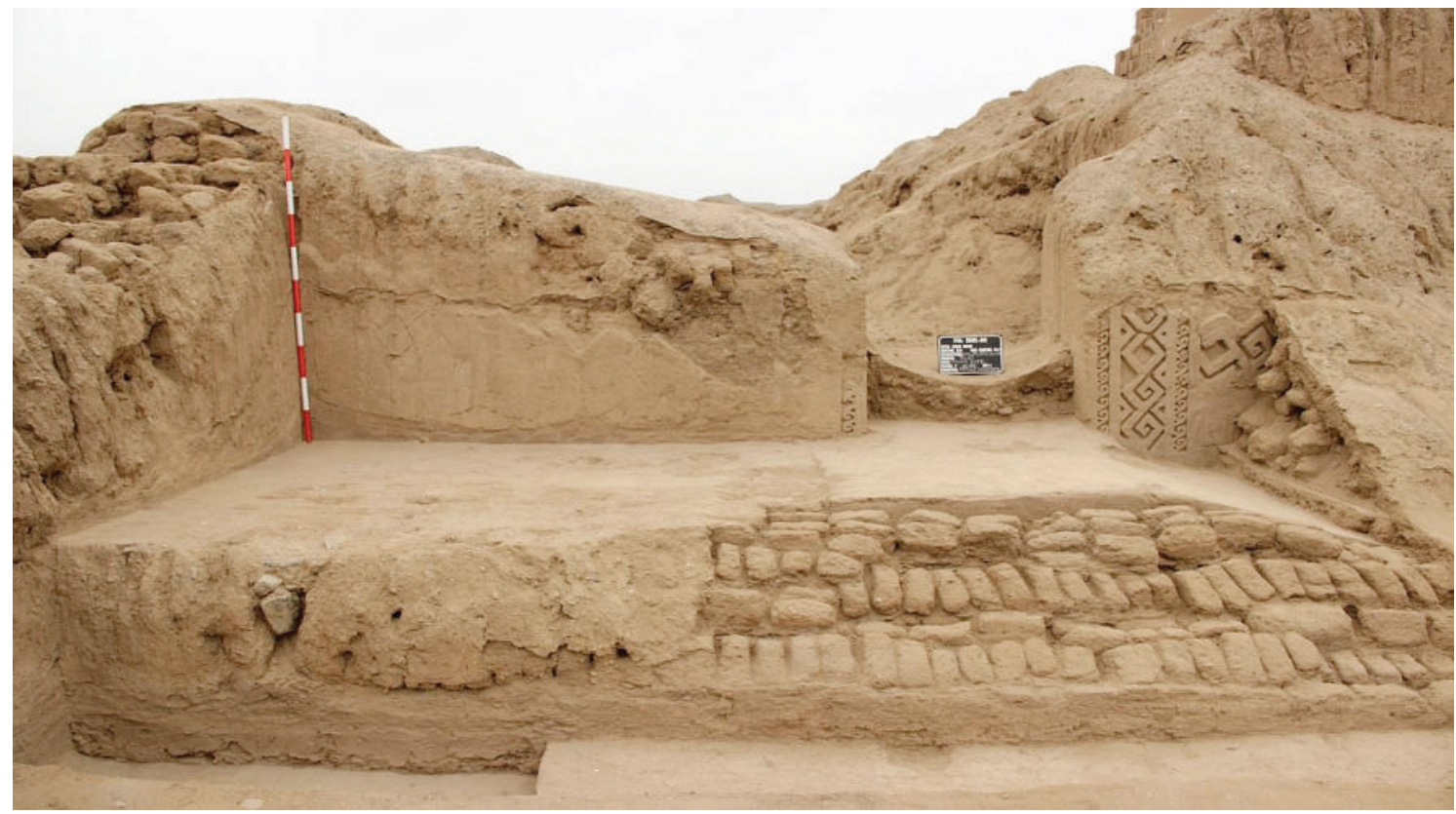

Figura 8. Acceso este a las audiencias registradas en el patio 7 con presencia de relieves decorativos con motivos geométricos y olas. Figure 8. East entrance to the hearings ("audiencias") recorded in courtyard 7 showing decoratives reliefs with geometrical motifs and waves.

\section{Los accesos}

Se logró delimitar nueve accesos a los diferentes patios y corredores. Sus medidas varían entre $1,58 \mathrm{~m}$ y $3,14 \mathrm{~m}$. En dos accesos se pudieron definir elementos decorativos, los cuales realzan estéticamente el ambiente y elevan el estatus del área en la cual se ubican y a la que preceden. Esto se observa en el acceso norte del patio 1 , donde se registran dos estructuras decorativas adosadas al muro norte, en las cuales posiblemente fueron colocados objetos móviles durante la realización de las ceremonias. Otro acceso es el del patio 7, en el que se observan relieves en las dos jambas que delimitan la entrada a las audiencias (fig. 8).

El paramento oeste de la jamba norte está cubierto por un enlucido sobre el cual se han realizado incisiones en forma de rombos con la finalidad de generar una fila de relieves a modo de olas estilizadas. Estas olas se orienten hacia el norte y hacen un total de tres olas completas y una incompleta. En el paramento oeste de la jamba sur se registraron cinco filas de relieves. En la primera fila se observa un total de nueve relieves en forma de olas, orientadas con dirección al norte; en la segunda fila se muestran cuatro rombos, dos completos y dos incom- pletos; en la tercera fila se presentan nuevamente los relieves en forma de olas con la misma orientación que las anteriores, con un total de once olas completas; en la cuarta fila se muestra un solo rombo, el que tampoco se encuentra cerrado y se halla incompleto; en la quinta fila se evidencia solo un rombo incompleto.

Durante el proceso de excavación se hallaron dos accesos sellados, en los patios 1 y 3 , ambos en los muros oeste de sus ambientes. En el patio 1 se registró un antiguo acceso de 1,36 $\mathrm{m}$ de ancho, que conectaba con un corredor al oeste del patio. Su clausura se realizó durante el tercer momento de construcción, con la finalidad de restringir el ingreso al patio y habilitar el paso oeste. Para su clausura se emplearon adobes dispuestos a tizón y canto con mortero, y luego enlucido (fig. 9). En el patio 3 , un acceso sellado se ubica en la zona central del muro oeste, el cual se encuentra relacionado con las jambas sur y norte. Presenta 1,30 m de ancho y la clausura de este acceso se realizó en el tercer momento de construcción, con el propósito de restringir la entrada al patio y habilitar los accesos norte y oeste. Para su clausura se colocó un relleno de tierra de $0,41 \mathrm{~m}$, sobre el primer piso, formando la base para el segundo piso del patio, el cual está asociado al tercer momento constructivo. 


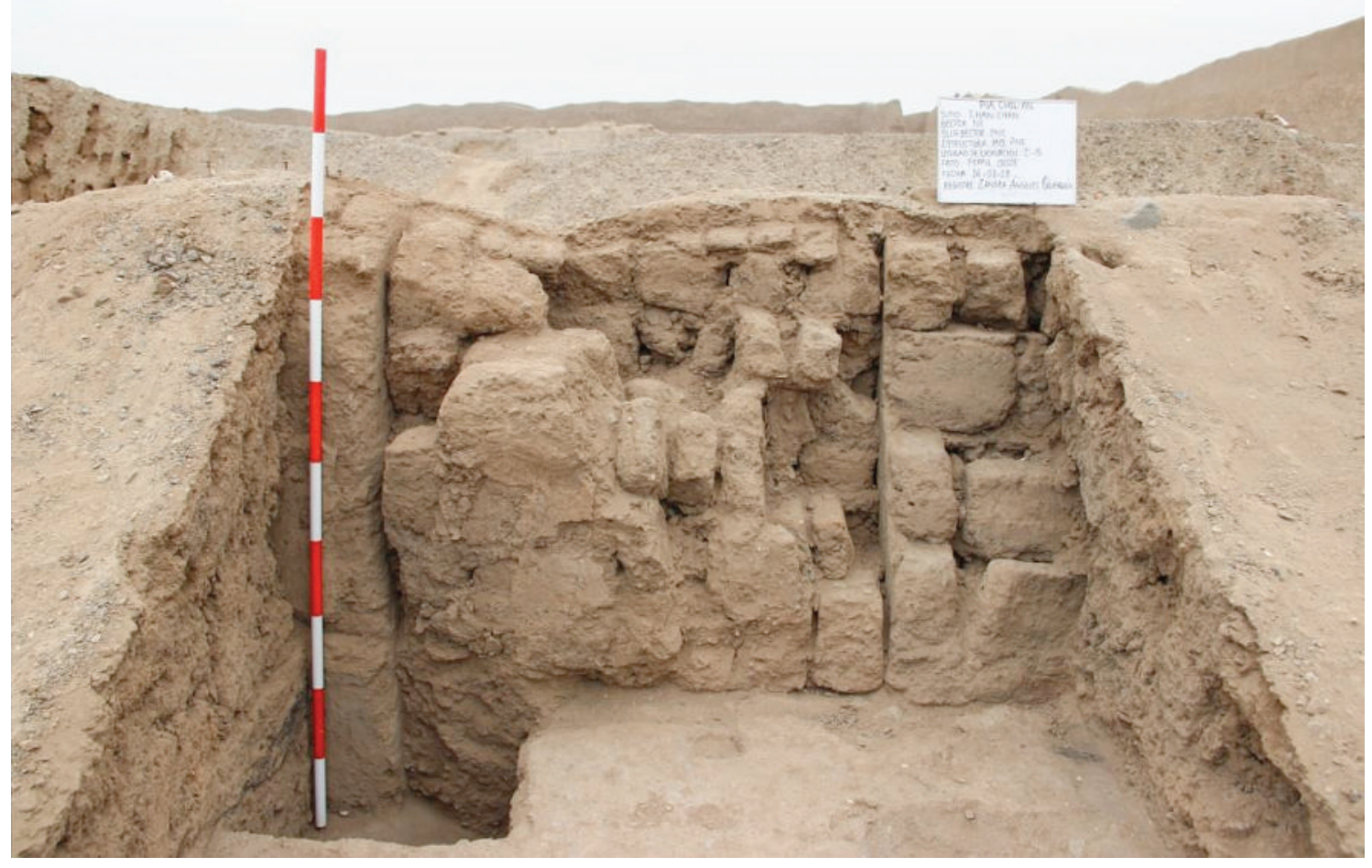

Figura 9. Acceso sellado en el patio 3 asociado con el tercer momento constructivo. Figure 9. Sealed entrance in courtyard 3 from the third building phase.

Luego se emplearon adobes dispuestos a tizón y canto con mortero, y posteriormente enlucidos. Durante la ocupación doméstica, se registró el desmontaje hasta la base de una sección del muro norte del patio 3 para abrir un acceso. En su entorno inmediato se observan pequeños muros y asociados junto a abudante basura doméstica.

\section{LOS MOMENTOS CONSTRUCTIVOS}

Según los datos registrados durante el proceso de excavación, la correlación entre los diferentes pisos de los ambientes y la información de las anteriores intervenciones en Chol An (Paredes 2013) es posible establecer cuatro momentos constructivos (fig. 10).

El primer momento constructivo corresponde a la elaboración del muro de tapia y los muros de adobes que delimitan el sur y el oeste del patio 3. Durante el segundo momento se construyeron los muros perimetrales y los patios. Para la construcción del patio 1 se desmontó parte del muro norte de tapia y se erigieron los muros del patio 1, y luego se adosaron las banquetas. Asimismo, se desmontó el muro sur y se delimitó el espacio para construir el patio 3. Producto de esta nueva distribución se selló el acceso ubicado en la parte central del muro oeste del patio y se realizó otro en el extremo norte del muro oeste. En el tercer momento se hicieron modificaciones en los patios 1 y 7 . En el patio 1 se selló el acceso oeste ubicado al sur del muro oeste, a modo de habilitar al norte del mismo muro un nuevo acceso. En el patio 7 se registró el cubrimiento de los relieves, ubicados en el muro este del patio, posiblemente relacionado con un cambio en la jerarquía de este espacio, disminuyéndose el área decorada. El cuarto momento correspondería al cambio en la funcionalidad de los patios. En el patio 1 se desmontó parte de la banqueta este para luego construir pequeñas estructuras, elaboradas de una sola hilada de adobe con acabados burdos.

En estos espacios se registró gran cantidad de restos culturales y áreas de quema, producto de las actividades de carácter doméstico realizadas en su 


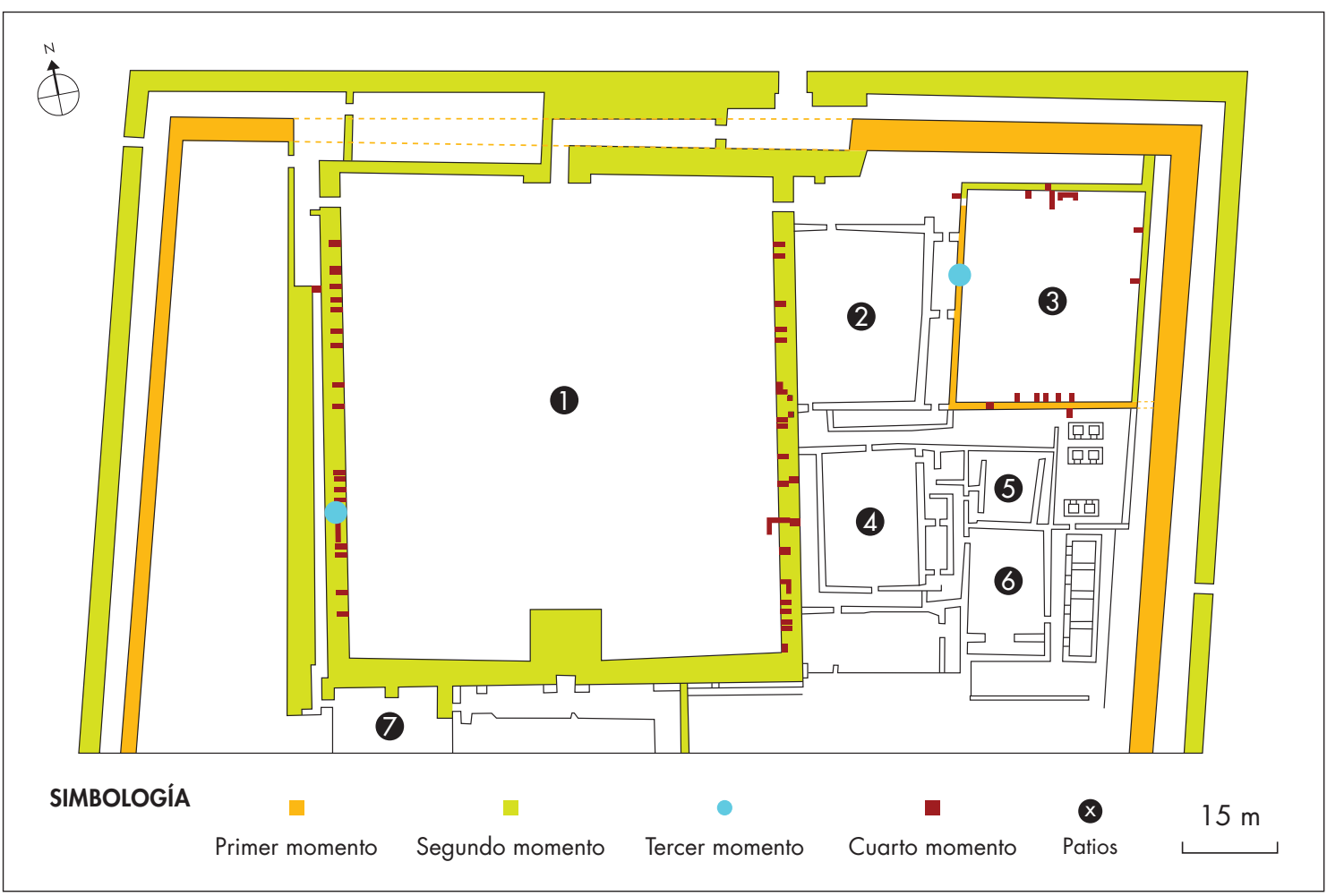

Figura 10. Momentos constructivos en la zona norte en el Conjunto Amurallado Chol An. Figure 10. Building phases in the northern part in the Chol An walled complex.

interior. Además, se desmontaron partes de los muros para generar nuevos accesos directos y, de esta forma, reordenar la conexión entre estos espacios y facilitar su uso. Se hallaron hornacinas y alacenas con acabados muy burdos en los muros cercanos a la reocupación y se registraron algunos contextos funerarios en las áreas cercanas a los patios 1 y 3 .

\section{DISCUSIÓN}

Un patrón arquitectónico en Chan Chan es la presencia de espacios abiertos sin cubierta, de grandes dimensiones, con estructuras decorativas y asociado a múltiples accesos incluidos. Esto fue posible registrar en los diez conjuntos amurallados (Campana 2006, 2012). La definición de este espacio ha originado un debate entre investigadores. Algunos lo denominan como "plaza" (Campana 2010, Gálvez \& Runcio 2010) y otros indican que estas características corresponden a patios (Ravines 1980a, Piminchumo \& Runcio 2009). Consideramos que el mejor concepto para catalogar este espacio es "patio", ya que se concibe arquitectónicamente como un lugar cerrado con paredes, iluminado y ventilado cenitalmente, en torno al cual se estructura un edificio (Díaz 1997, Silva 2001). Caso totalmente contrario es la plaza, definida como un espacio público que se encuentra bajo el dominio de un Estado, el cual domina y regula su uso para las actividades humanas de carácter público (Gehl \& Svarre 2013). Al respecto, lo "público" se considera arquitectónicamente como un espacio que es accesible a todos los habitantes de una ciudad (Durán \& Vanegas 2015). Al reconocer a los conjuntos amurallados como unidades arquitectónicas, podemos proponer que todos los espacios abiertos dentro de ellos son patios. Además, es posible observar que, si bien estos espacios abiertos fueron proyectados con fines ceremoniales para congregar a parte de la población de Chan Chan, se debe recordar que estas actividades se desarrollaban en un ambiente privado delimitado por grandes muros perimetrales y que se debía seguir un determinado recorrido por intrincados corredores dentro 


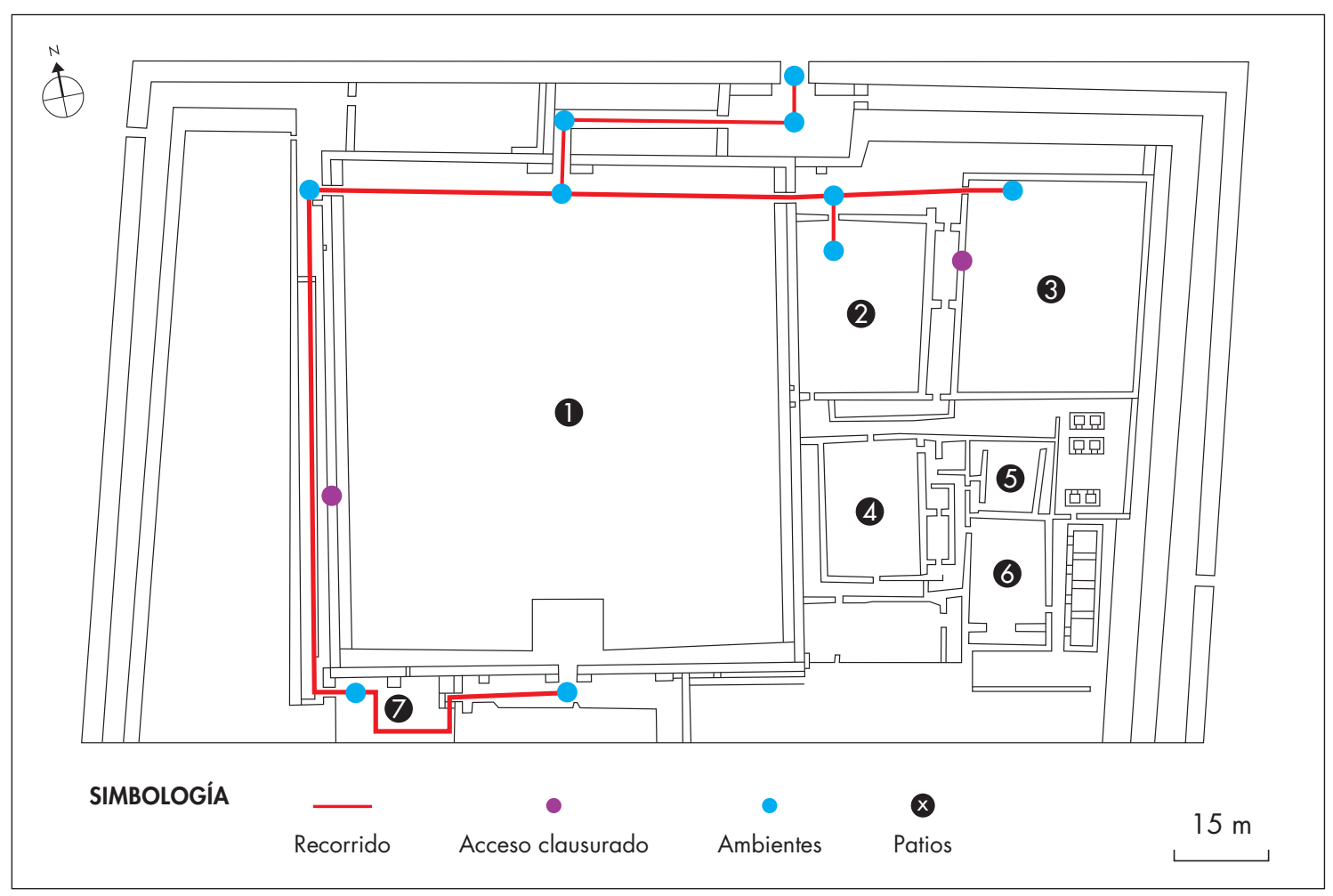

Figura 11. Posible recorrido en los patios norte del Conjunto Amurallado Chol An. Figure 11. Possible route in the northern courtyards of the Chol An Walled Compound.

de los conjuntos amurallados para acceder a ellos. La conexión entre los patios y las demás áreas (audiencias, depósitos, plataformas funerarias y huachaques) eran reflejo del control de los espacios que el gobernante chimú planificaba constantemente durante la construcción y ocupación de esta unidad arquitectónica.

\section{Recorrido en los patios}

En el Conjunto Amurallado Chol An se logró definir el recorrido realizado para ingresar a los patios norte durante el segundo y tercer momento constructivo (fig. 11). Este se organizaba de la siguiente manera: el acceso principal a Chol An era el primer punto, ingresando a un corredor con dos banquetas; luego se dirigían al oeste hacia un segundo corredor con dos ambientes. Estos ambientes posiblemente eran antesalas para el ingreso de los individuos al patio 1 y funcionaban como áreas de preparación previa. Posteriormente se ingresaba al patio 1 (el más grande de todo el conjunto), zona donde se realizaban las ceremonias.
Asociados con este gran patio fueron registrados tres accesos habilitados y uno sellado. Estos se articulaban con diferentes ambientes en el área norte y sur del conjunto. Por el lado oeste, se logró determinar que, durante el segundo momento constructivo, existía un acceso en el lado sur del muro oeste del patio 1 que conectaba con un corredor con banqueta, el cual era utilizado por el personal encargado de las ceremonias y desde donde se suministraban los recursos durante dichas actividades, siendo empleado luego por los visitantes como una vía de circulación para acceder a espacios más restringidos, como el patio 7. Posteriormente, durante el tercer momento, este acceso fue sellado y se habilitó uno nuevo al norte, que conectaba con una explanada, con el corredor con banqueta y con el patio 1 .

$\mathrm{Al}$ ingresar al patio 7, es posible observar una estructura decorativa al norte y una rampa con banqueta que da paso al área de audiencias. Los paramentos oeste de las jambas presentan relieves el ingreso, siendo de mayor amplitud la decoración durante el segundo momento constructivo, pero luego el paramento fue 
enlucido durante el tercer momento constructivo, reduciéndose su amplitud.

Las ceremonias eran dirigidas desde el lado sur del patio 1. Aquí se ubicaba una banqueta con rampa, situada a $1,30 \mathrm{~m}$ sobre el nivel del piso del patio 1 . El ingreso de los oficiantes a las ceremonias en este patio mediante el acceso sur generaba un importante impacto visual. Se trataba de personajes de alta jerarquía que podían acceder a las zonas de mayor privacidad y conocían la articulación de los espacios; prueba de ello es que, al ingresar por el sur, se entraba directamente al área de audiencias y se evitaba todo el recorrido por el oeste, logrando controlar y diferenciar el tránsito de las personas que ingresaban a los demás espacios dentro de Chol An respecto de los que trabajaban.

Por el lado este en el patio 1 se ingresaba a un corredor que conectada con los patios 2 y 3 . Estos espacios fueron de mayor restricción y aquí se realizaban ceremonias más privadas. Estos ambientes eran los primeros niveles de restricción para acceder a un conjunto de patios con mayor nivel de privacidad, como son los patios 4, 5 y 6 .

Según lo dicho, es posible establecer dos hechos principales, el manejo de los espacios y su uso. El primero se relaciona con el control que tuvieron los chimús para la planificación del recorrido, el cual generaba diferentes grados de restricción entre cada patio. Todo esto marcaba claras diferencias entre los indirectos recorridos que los visitantes estaban obligados a seguir y el directo manejo estratégico de los ambientes que los anfitriones desarrollaban para generar una elevada fluidez en su tránsito.

En cuanto al uso del espacio, se observa una diferencia marcada con respecto a las dimensiones de los patios y es posible deducir que esto se encuentra directamente relacionado con la mayor o menor restricción de las actividades que se realizaban en estos lugares. El patio 1 representó el nivel más bajo de restricción, seguido por los patios 2 y 3 , siendo mucho más limitado el acceso al patio 7 que, al considerar sus elementos decorativos como un indicador de jerarquía (Piminchumo \& Runcio 2009), es posible asociarlo con prácticas ceremoniales diferenciadas con respecto de los otros patios. Todos estos espacios eran supervisados en todo momento por los agentes estatales desde zonas estratégicas para corroborar y controlar el desarrollo adecuado de las ceremonias. La función articuladora de los patios también fue documentada en el Conjunto Amurallado Nik An, donde se logró determinar que, la jerarquización de estos espacios abiertos, estuvo relacionada con la cantidad de personas que participaban en las ceremonias (Gálvez \& Runcio 2010). De esta manera, es posible suponer que la existencia de banquetas en los ambientes que anteceden a los patios indicaría que el ingreso a estas áreas no era de forma directa, sino que se retenía a los visitantes por algunos momentos dentro de los corredores y eran necesarias zonas de reposo donde podrían colocar de manera temporal el tributo que llevaban consigo.

\section{Ambientes, estructuras y elementos arquitectónicos}

Las estructuras decorativas, denominadas también machones (Campana 2012:2), se encuentran en los accesos a los patios de mayor jerarquía, estando vinculadas con el manejo social de la arquitectura por parte del gobernante y con la ostentación ante los individuos que ingresaban al conjunto amurallado. Similares estructuras se registraron en los patios asociados con audiencias en el Conjunto Amurallado Nik An (Galvez \& Runcio 2010). Aunque no se demostró evidencia de pigmentos, es muy probable que originalmente presentaran pintura, ya que se logró identificar el uso de diversos pigmentos dentro de la capital Chimú (Pillsbury 1993, 1994).

Con relación a la construcción de los muros en los patios 1 y 3 , fue posible observar que los muros que delimitan estos ambientes fueron hechos en bloques de $5 \mathrm{~m}$. Posteriormente, eran tramados en la parte superior (cabecera) con las demás secciones y así lograban unir todos los segmentos del muro (fig. 12), recibiendo al final un acabado con mortero de barro. Esto indica que la construcción de las estructuras en el conjunto amurallado fue realizada por segmentos bajo la modalidad de grupos de trabajos, y mediante una forma de tributación asignada (Moseley 1975) y de carácter rotativo (Rostworowski 2005).

En la construcción de los muros de los patios 1 y 3 se registró el uso de Phragmites australis "carrizo" y Gynerium sagittatum "caña brava" en los muros este y oeste. Si bien se considera que se utilizaron estos vegetales a fin de orientar y guiar el crecimiento vertical de estos muros (Campana 2012), el empleo del carrizo, caña brava o caña de Guayaquil se advierte en otros conjuntos amurallados, tanto para muros internos (Rodas 2008, Cueva 2011) como perimetrales (Otiniano 2008, Gonzales 2009, Seminario 2010, Rodas 2013). No es posible determinar algún tipo de patrón o recurrencia en la ubicación y distancia que pueda originar algún 


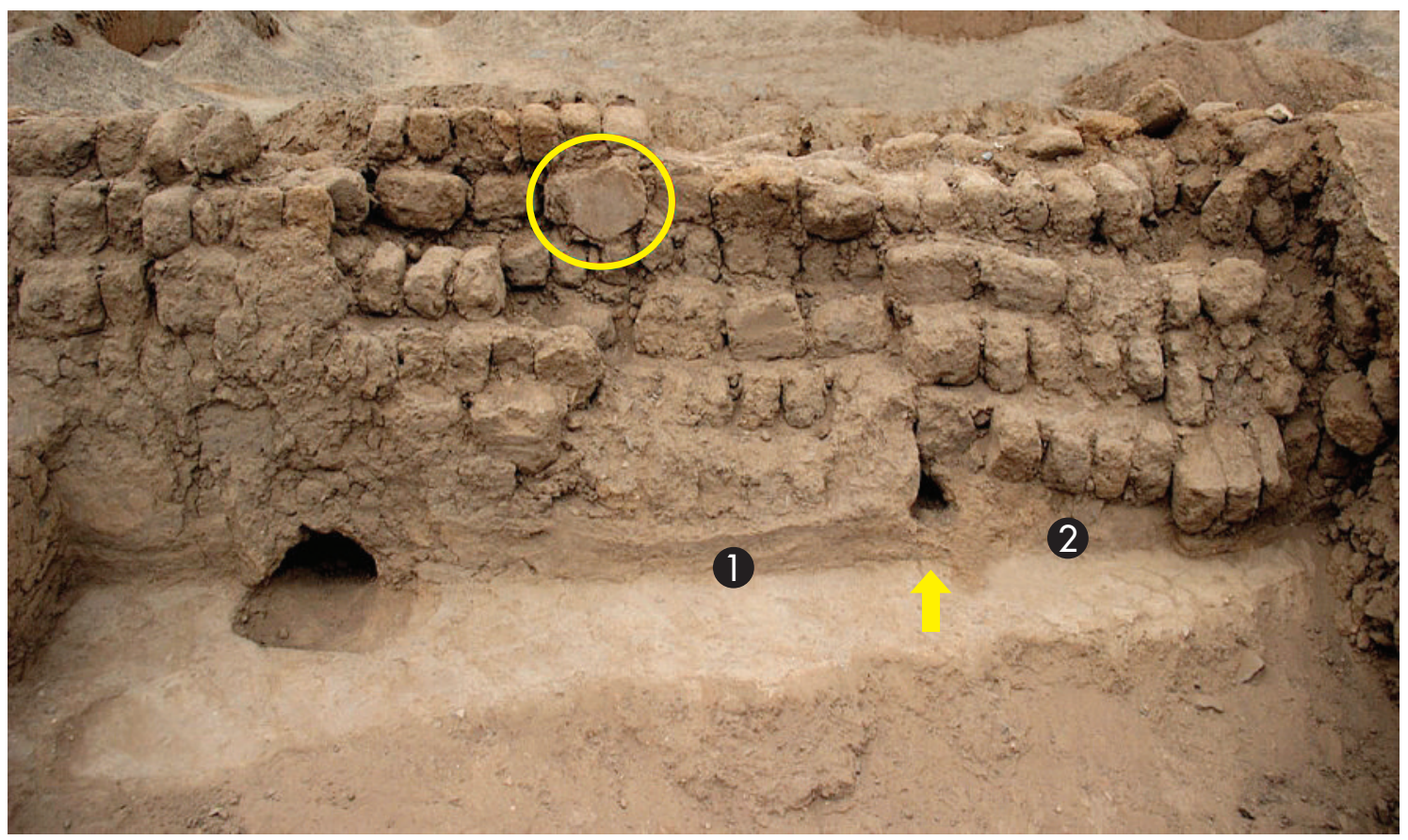

Figura 12. Vista de los bloques constructivos en la elaboración del muro este del patio 1 y el uso de adobes reutilizados. Figure 12. View of the building blocks in the construction of the east wall in courtyard 1 and the use of reused adobe (mud bricks).

punto de referencia. Consideramos que la presencia de carrizo en los patios 1 y 2 no se encuentra asociada al guiado de las estructuras, ya que no se evidencia ningún ordenamiento entre cada uno de ellos y las edificaciones, por lo tanto, su funcionalidad original es desconocida por ahora (fig. 13).

En diversos muros se observó el empleo de adobes dispuestos de canto, posición vinculada con la necesidad de lograr en poco tiempo mayor altura en las estructuras. En los muros norte, este y oeste del patio 1 se detectaron tres tipos de acabados en el paramento interno: emporrado, fratasado y pulido (fig. 14). Con relación al patio 3, se registraron dos tipos de acabados: fratasado y pulido, en los dos paramentos del muro sur, pero la naturaleza de su elaboración difiere a lo identificado en el patio 1. El fratasado, corresponde a un revestimiento continuo (acabado burdo), se localiza en la parte inferior del paramento y superpuesto al pulido, quedando estos dos tipos de acabados claramente separados por la impronta del escombro que quedó en el paramento. Se propone que el muro originalmente tuvo un enlucido pulido y posteriormente, durante la ocupación doméstica, se realizó el fratasado, cubriendo el enlucido original, posiblemente con la finalidad de resanar el paramento de la estructura se estaba reocupando. Luego el muro colapsó y con el tiempo se cubrió de escombros la parte inferior de la estructura, quedando la sección superior expuesta a las inclemencias climáticas. Esto permitió que el fratasado se erosionara y dejara a la vista el enlucido original, mientras que en la sección inferior, los escombros protegían el acabado tardío.

Durante la ocupación tardía hubo desmontaje de estructuras, como es el caso de la banqueta este en el patio 1. Esto se logró corroborar con la presencia de dos tipos de enlucidos en los paramentos de los muros norte y este que delimitan el patio 1 . Se observó un enlucido burdo desde el piso hasta una altura de 0,40 $\mathrm{m}$; sobre esta medida se advierte un mejor acabado (pulido). Esto se debe a que la banqueta presentaba 0,40 m de altura, siendo la parte burda el área donde la banqueta se adosaba al muro. Esto no solamente se relaciona con la reocupación de los patios mediante la reutilización de adobes, producto del desmontaje de otras estructuras, sino también con los diferentes momentos constructivos. Se registró que las piedras provenientes del desmontaje del muro de tapia norte, 


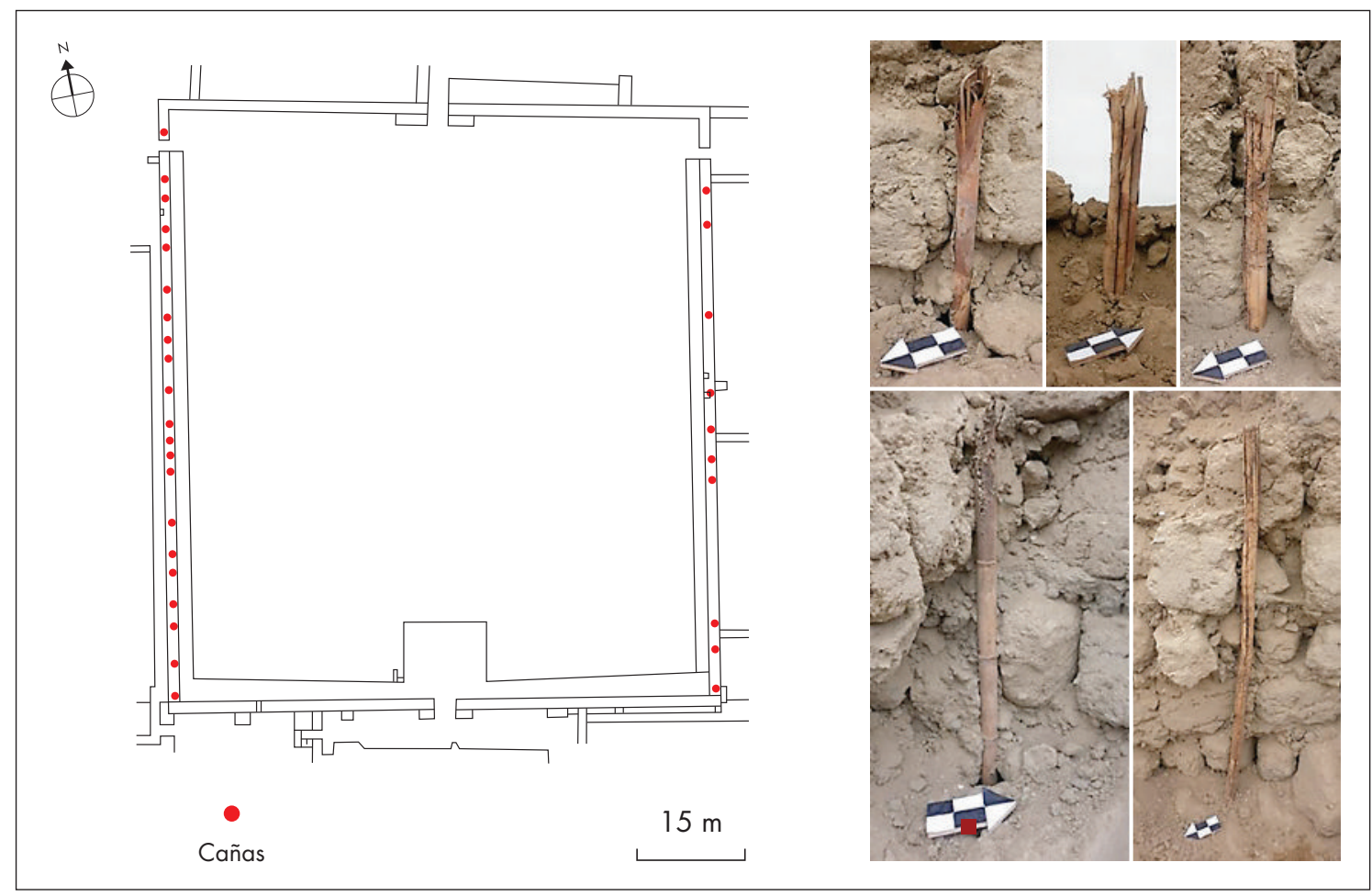

Figura 13. Presencia de cañas en los muros oeste y este del patio 1 (izquierda). Figure 13. Presence of reeds in the east and west walls in courtyard 1 (left).

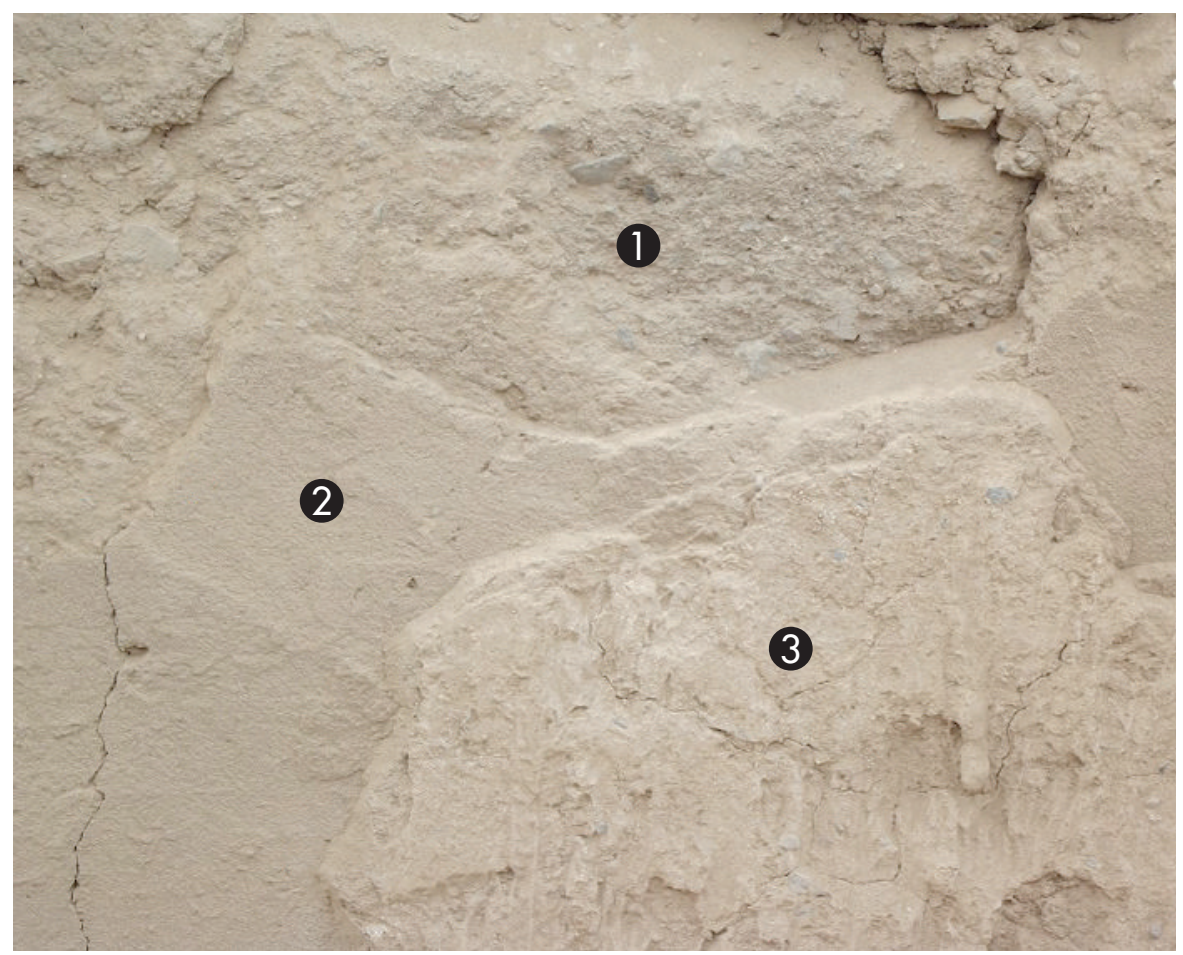

Figura 14. Detalle en el muro donde se registraron los 3 tipos de acabados en el Conjunto Amurallado Chol An: a) emporrado; b) pulido; c) fratasado. Figure 14. Detail of the wall where the three types of finish were recorded in the Chol An Walled Compound: $\boldsymbol{a})$ plaster; $\boldsymbol{b}$ ) polished; c) floating. 

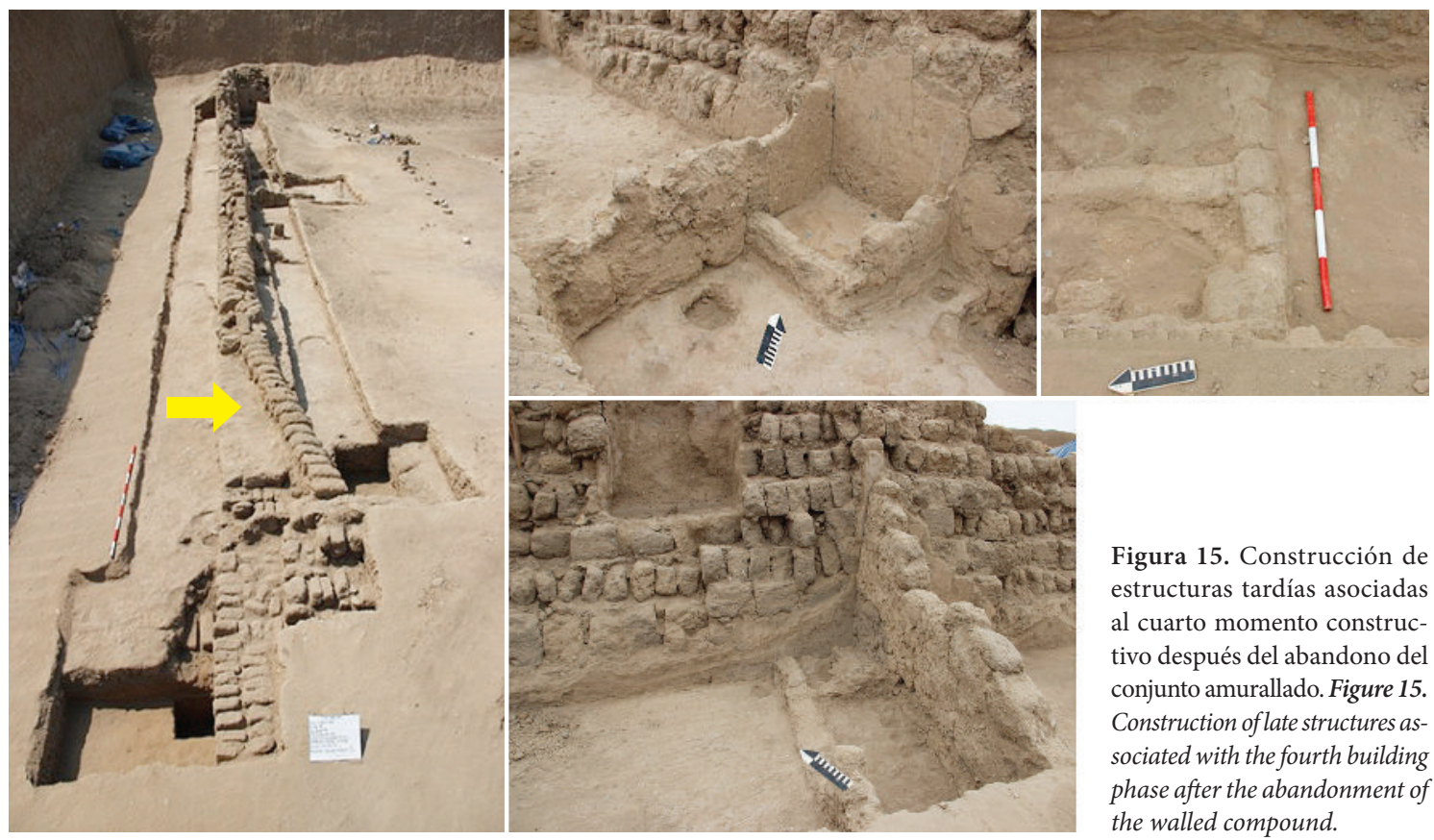

Figura 15. Construcción de estructuras tardías asociadas al cuarto momento constructivo después del abandono del conjunto amurallado. Figure 15. Construction of late structures associated with the fourth building phase after the abandonment of the walled compound.

vinculadas con el primer momento constructivo, fueron utilizadas como base para el muro norte del patio1.

Además, se observa el empleo de adobes de segunda mano (con fragmentos de enlucido) y la aplicación de mortero de barro con pequeñas piedras (pachillas), logrando una superficie uniforme para el asentado de adobes. Los adobes utilizados en la construcción de las estructuras tardías fueron empleados para elaborar muretes simples, generalmente de una sola hilada, con un enlucido muy burdo. La reutilización de adobes es recurrente, tanto para el segundo momento constructivo como para la reocupación doméstica (cuarto momento). La diferencia se basa en que, mientras el primero fue realizado durante el pleno desarrollo cultural chimú, el segundo ocurrió luego del colapso de la capital y a raíz de las invasiones ocurridas en Chan Chan luego del abandono.

\section{Reocupación y uso de los espacios}

La ocupación doméstica registrada al interior de los diferentes ambientes implicó un cambio radical, tanto arquitectónico como funcional, de este conjunto amurallado. Esto se debió al abandono durante un período de crisis y al colapso de la clase gobernante chimú. En ese período se aprovecharon los diversos ambientes y vías de comunicación para construir improvisadas viviendas, pues el diseño arquitectónico permitía una rápida modificación del espacio a fin de lograr satisfacer diferentes necesidades. Según lo intervenido, la ocupación estuvo centrada en la parte norte de Chol An, lugar donde se observa una reutilización de los ambientes y elementos arquitectónicos, como son las banquetas y corredores, sobre los cuales se desarrollaron actividades domésticas. En algunas ocasiones destruyeron muros y elementos arquitectónicos para construir viviendas (fig. 15).

Un claro ejemplo es la banqueta sur de la explanada norte, desmontada casi en su totalidad, registrándose en dicho ambiente una fuerte actividad doméstica. Otro caso es la banqueta este del patio 1, donde en algunos tramos fueron construidas estructuras tardías (muretes) sobre ella, y acondicionado el muro este para la elaboración de hornacinas y alacenas. En estos contextos se encontraron restos de materiales culturales muebles como fragmentos de cerámica doméstica (platos, ollas, cántaros, etc.) con formas que se encuentran vinculadas al Período Chimú-Inca, como el cuello carenado (Tello \& Zavaleta 2011) (fig. 16).

En estos contextos domésticos también se detectaron restos óseos de cuy, pescados y camélidos, entre otros. Algunos con cortes, indicarían el despresamiento del animal para su posterior consumo. Asimismo, se 

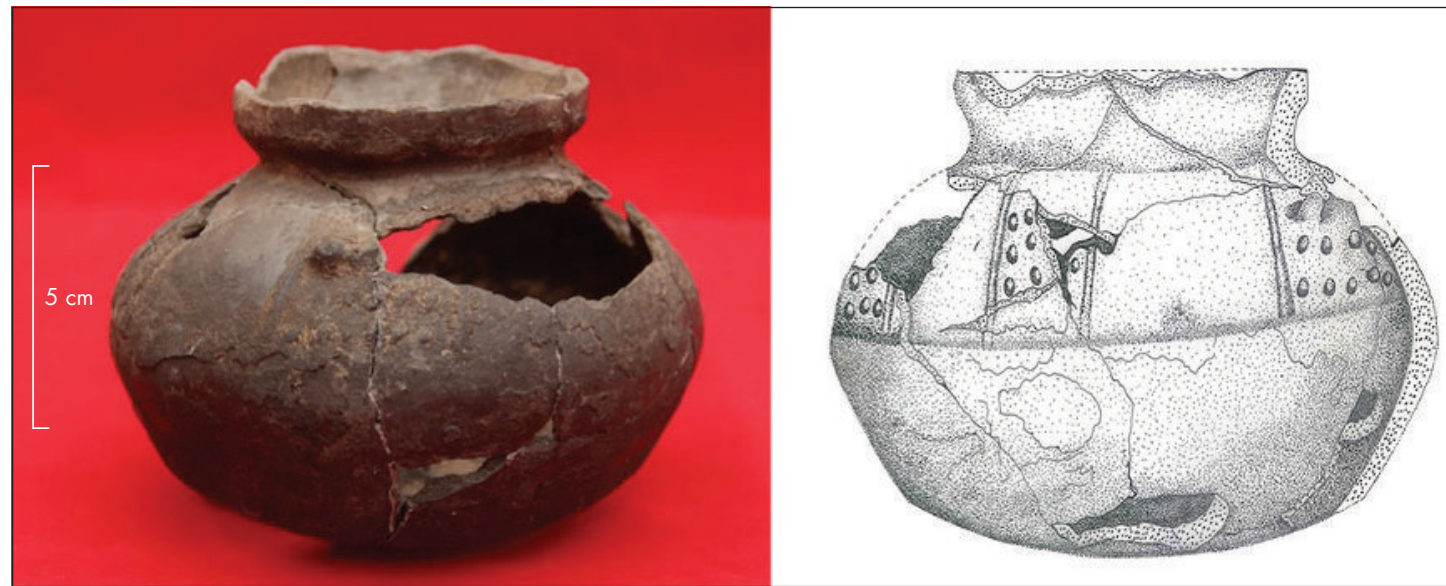

Figura 16. Vasija con cuello carenado registrado en el patio 1, asociado al Período Chimú-Inca. Figure 16. Vessel with faired neck recorded in courtyard 1, associated with the Chimu-Inca Period.

recuperaron algunos utensilios textiles como agujas y paletas, fragmentos de textiles, restos vegetales como fibras de Gossypium barbadense "algodón" procesado y semillas de frutas comestibles como Annona muricata "guanábana" y Pouteria lucuma "lúcuma" (fig. 17). Todo esto puede ser considerado, sin lugar a dudas, como restos de basura producto de la actividad diaria, los que fueron dejados luego del abandono definitivo de estos espacios. Este comportamiento se observa en todas las áreas que se relacionan con la ocupación doméstica. Contextos similares han sido reportados en otros conjuntos amurallados, como Xllangchic An (Cueva 2011) y Utzh An (Castillo 2018), que fueron asociados con el Período Chimú-Inca y en un escenario donde se reocuparon las áreas ceremoniales antes restringidas para ser modificadas y utilizadas como áreas de viviendas improvisadas.

Producto de las investigaciones realizadas por Day se determinó que el patio 2 estaba destinado para la preparación de alimentos, denominado por el investigador como "patio de cocina" (Day 1980: 156), pero no se pudo tener acceso a la información de las excavaciones realizadas en este sector y solamente se dispone de las conclusiones publicadas (Day 1980, 1982). Según la ubicación estratigráfica de los materiales recuperados durante la presente investigación, se señaló que, posiblemente, se trate de un área de preparación de alimentos, pero asociada a la reocupación doméstica luego del abandono de conjunto amurallado. Las excavaciones realizadas durante la presente temporada fueron limitadas y no fue posible registrar ningún tipo de material que indicara la clase de uso del espacio durante la ocupación pre-abandono. Esta interrogante podría ser resuelta en futuras investigaciones, cuando se realicen excavaciones en área dentro de este patio.

\section{CONCLUSIONES}

A partir de los resultados obtenidos durante las excavaciones fue posible determinar la presencia de cuatro momentos constructivos, los dos primeros vinculados a la construcción inicial del conjuntoa amurallado, el tercero con el desarrollo pleno de las actividades culturales y el cuarto con la reocupación de los espacios abiertos luego del abandono de Chan Chan. Estos momentos se reflejaron en la conectividad entre los patios y los ambientes colindantes, y la evidente la clausura y apertura de accesos, con el objetivo de satisfacer distintas necesidades presentes en los diferentes momentos constructivos.

Teniendo en cuenta los resultados obtenidos en anteriores intervenciones, es posible considerar que, si bien el patio 2 se usó como un área de cocina, según la correlación estratigráfica, no corresponde al Período Chimú, sino a las invasiones realizadas a los conjuntos amurallados luego de que estos fueran abandonados. Los patios de la parte norte del Conjunto Amurallado Chol An estuvieron relacionados con las ceremonias político-religiosas organizadas por el gobernante 


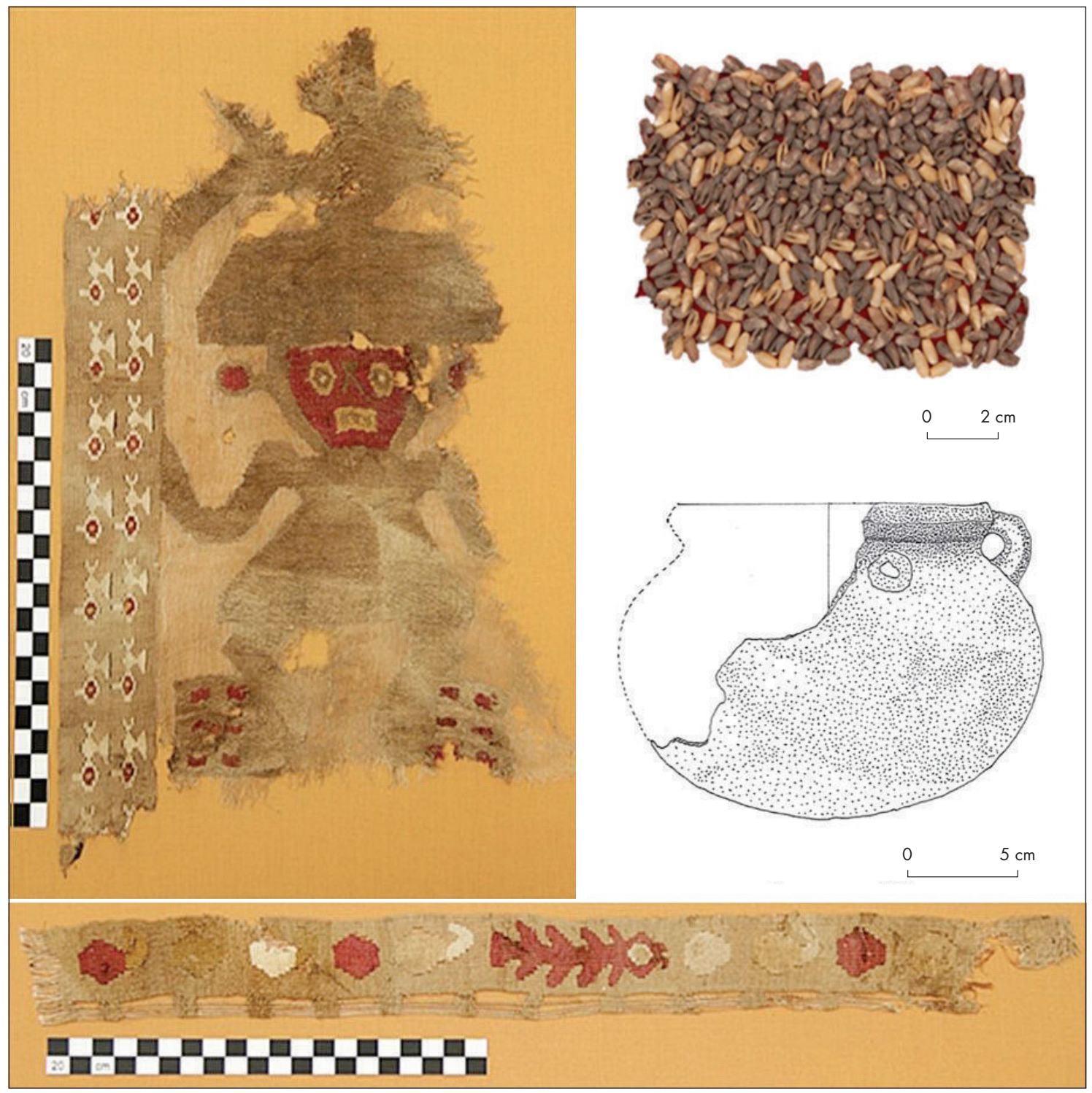

Figura 17. Olla con cuello carenado, restos de Olivella columellaris quemadas y textiles asociados a los contextos tardíos durante el cuarto momento constructivo. Figure 17. Pot with faired neck, remains of burnt Olivella columellaris and textiles associated with the later contexts during the fourth building phase.

chimú que habitada en este conjunto. Producto de dicho uso público tuvieron la necesidad de realizar construcciones decorativas para demostrar su poder económico a los visitantes. La materialización de esta necesidad son los relieves con motivos geométricos y de olas en el patio 7, asimismo, las estructuras decorativas en los patios 1 y 7. La gran majestuosidad de los conjuntos amurallados fue muy significativa para los habitantes de Chan Chan que, luego del abandono de todos estos espacios restringidos, fueron reocupados y los adaptaron para su utilización doméstica. En la parte norte de Chol An es posible percatarse de que construyeron pequeñas estructuras y se reutilizaron los patios 1 (banquetas), 2 y 3 . En estos espacios se hallaron fragmentos de cerámica vinculadas con la fase estilística Chimú-Inca, restos de textiles, óseos, malacológicos y vegetales, todos los cuales que fueron utilizados por los nuevos habitantes. 
Agradecimientos Deseamos expresar nuestra gratitud a los arqueólogos que apoyaron el desarrollo de la presente investigación, tanto en la temporada que presentamos como durante todos los trabajos de intervención arqueológicas realizados en el Conjunto Amurallado Chol An. Un agradecimiento en particular para el arqueólogo Eduardo Eche Vega por la revisión y las sugerencias al texto.

\section{REFERENCIAS}

Campana, C. 2006. Chan Chan del Chimo. Estudio de la ciudad de adobe más grande de América antigua. Lima: Orus.

Campana, C. 2010. Chan Chan: nuevos hallazgos, nuevas hipótesis. Pueblo Continente 21 (1): 27-52.

Campana, C. 2012. Arquitectura y ceremonia en Chanchan. Trujillo: Fondo Editorial de la Universidad Privada Antenor Orrego.

Castillo, F. 2018. Excavaciones en el Conjunto Amurallado Utzh An (ex Gran Chimú). En Programa de investigación arqueológica, conservación y puesta en valor. Informe anual 2017, N. Gamarra, Ed., pp. 403-520. Trujillo: Proyecto Especial Complejo Arqueológico Chan Chan.

Cornejo, L., Sinclaire, C., Alcaino, R. \& Vial, J. 2005. Chimú: laberintos de un traje sagrado. Santiago: Museo Chileno de Arte Precolombino.

Cueva, S. 2011. Proyecto Investigación Arqueológica, conservación y restauración de los muros perimetrales, del sector este del Conjunto A murallado Xllangchic An (ex palacio Uhle), del Complejo Arqueológico Chan Chan. Informe final. Trujillo: Proyecto Especial Complejo Arqueológico Chan Chan.

DAY, K. 1973. Architecture of ciudadela Rivero, Chan Chan, Peru. Cambridge: Harvard University.

DAY, K. 1980. Las ciudadelas de Chan Chan. En Chan Chan metrópoli chimú, R. Ravines, Comp., pp. 255-258. Lima: Instituto de Estudios Peruanos-Instituto de Investigación Tecnológica Industrial y de Normas Técnicas.

DAY, K. 1982. Ciudadelas: their form and function. En Chan Chan: andean desert city, M. Moseley \& K. Day, Eds., pp. 55-66. Albuquerque: School of American Research Book-University of New Mexico Press.

DíAz, G. 1997. La tradición del patio en la arquitectura moderna. Documents de Projectes d'Arquitectura 13: 6-11.

Durán, M. \& VAnegas, N. 2015. Espacio público en zonas de patrimonio débil: regeneración arquitectónico-urbana de la plaza El Otorongo y la plaza del Herrero. Cuenca: Universidad de Cuenca.

GÁLVEZ, C. \& Runcio, M. 2010. El caso de los recintos ceremoniales de Nik An-Sector norte. Iconografía, arquitectura y uso del espacio en Chan Chan. Arkinka 171: 88-92.

GehL, J. \& Svarre, B. 2013. How to study public life: methods in urban design. Washington: Island Press.
Gonzales, G. 2009. Proyecto de restauración de los muros perimetrales norte, este y oeste del conjunto, y muro perimetral del recinto funerario, Conjunto Amurallado Ñain-an (ex Bandelier), Complejo Arqueológico Chan Chan. Informe final, I etapa. Trujillo: Unidad Ejecutora 110, Complejo Arqueológico Chan Chan.

KolatA, A. 1980. Chan Chan: crecimiento de una ciudad antigua. En Chan Chan: metrópoli chimú, R. Ravines, Comp., pp. 130-154. Lima: Instituto de Estudios PeruanosInstituto de Investigación Tecnológica Industrial y de Normas Técnicas.

Moore, J. \& Mackey, C. 2008. The Chimú empire. En Handbook of south american archaeology, H. Silverman \& W. Isbell, Eds., pp. 783-807. Nueva York: Springer.

Moseley, M. 1975. Chan Chan: andean alternative of preindustrial city. Science 187: 219-225.

Moseley, M. \& DAY, K. 1982. Chan Chan: andean desert city. Albuquerque: School of American Research Book, University of New Mexico Press.

Otiniano, V. 2008. Proyecto de Investigación y conservación del muro perimetral en el Conjunto Amurallado Nain-an (ex palacio Bandelier), en los sectores centro oeste y sur, y muro divisorio de los sectores centro y sur, Complejo Arqueológico Chan Chan. Informe final. Trujillo: Unidad Ejecutora 110, Complejo Arqueológico Chan Chan.

Paredes, A. 2010. Complejo Arqueológico Chan Chan: los conjuntos amurallados y sus nominaciones. Pueblo Continente 21 (1): 53-71.

PARedes, R. 2013. Proyecto de Investigación para la conservación de muros perimetrales, Plaza Ceremonial 1, Patio Noreste y Plataforma Funeraria del Conjunto Amurallado de Chol-An, Complejo Arqueológico de Chan Chan. Informe final. Trujillo: Unidad Ejecutora 006, Complejo Arqueológico Chan Chan.

Pillsbury, J. 1993. Sculpted friezes of the Empire of Chimor. Nueva York: Columbia University.

Pillsbury, J. 1994. Los relieves en Chan Chan. Nuevos datos para el estudio de la secuencia y ocupación de la ciudad. Revista del Museo de Arqueología, Antropología e Historia 5: 47-80.

Piminchumo, V. \& Runcio, M. 2009. Espacios ceremoniales tardíos en Chan Chan: el caso de los patios delanteros de audiencias en el Conjunto Amurallado Nik An (ex Tschudi). Arkinka 162: 106-111.

RAvines, R. 1980a. Chan Chan: metrópoli chimú. Lima: Instituto de Estudios Peruanos-Instituto de Investigación Tecnológica Industrial y de Normas Técnicas.

Ravines, R. 1980b. La ciudad y sus habitantes. En Chan Chan: metrópoli chimú, R. Ravines, Comp., pp. 105-129. Lima: Instituto de Estudios Peruanos, Instituto de Investigación Tecnológica Industrial y de Normas Técnicas.

Risco, L. 2013. Sistema agrícola chimú en pampas de Huanchaco. Trujillo: Universidad Nacional de Trujillo. 
RodAs, W. 2008. Proyecto de Investigación y conservación en el Conjunto Amurallado Nik An (ex palacio Tschudi), Complejo Arqueológico Chan Chan: Audiencias (sector norte), Plataforma funeraria adosada (sector sureste), Muro perimetral. Informe final. Trujillo: Unidad Ejecutora 110, Complejo Arqueológico Chan Chan.

RoDAs, W. 2013. Proyecto de Investigación arqueológica y conservación de los muros perimetrales del Conjunto Amurallado Fechech An (ex Laberinto), Complejo Arqueológico Chan Chan. Informe final, I etapa. Trujillo: Proyecto Especial Complejo Arqueológico Chan Chan.

Rostworowski, M. 2005. Redes económicas del Estado Inca: el "ruego" y la "dádiva". En El Estado está de vuelta: desigualdad, diversidad y democracia, V. Vich, Ed., pp. 13-47. Lima: Instituto de Estudios Peruanos.

Rostworowski, M. 2011. Pachacutec Inca Yupanqui. Lima: Instituto de Estudios Peruanos.

Seminario, E. 2010. Proyecto Perimetrales del Conjunto Amurallado Ñing An-ex palacio Velarde, Complejo Arqueológico Chan Chan. Informe final, I etapa. Trujillo: Unidad Ejecutora 110, Complejo Arqueológico Chan Chan.
Silva, M. 2001. La vivienda a patios de origen hispánico y su difusión en Iberoamérica. En Actas del III Congreso Internacional del barroco americano: territorio, arte, espacio y sociedad, pp. 875-896. Universidad Sevilla: Universidad Pablo de Olavide. Sevilla. <https://www.upo.es/depa/ webdhuma/areas/arte/3cb/documentos/071f.pdf $>$ [consultado: 14-01-2020].

Soberón, F. 2014. Proyecto de investigación para la conservación de la plaza ceremonial 1 y patio noreste del Conjunto Amurallado de Chol An-Complejo Arqueológico de Chanchan. Informe final. Trujillo: Unidad Ejecutora 006, Complejo Arqueológico Chan Chan.

Tello, R. \& Zavaleta, E. 2011. Informe final de análisis de cerámica del proyecto de restauración de los muros perimetrales, del sector este del Conjunto Amurallado Xllangchic An (ex palacio Uhle), del Complejo Arqueológico de Chan Chan, Provincia de Trujillo, Región La Libertad-II etapa. Trujillo: Unidad Ejecutora 110, Complejo Arqueológico Chan Chan.

VArgas, R. 1936. La fecha de la fundación de Trujillo. Revista Histórica: 229-239. 